\title{
IGLESIA, PODER MUNICIPAL Y FUNDACIÓN DE CAPELLANÍAS EN CALAHORRA (1600-1710)
}

\author{
JULIO LUIS ARROYO VOZMEDIANO
}

Departamento de Historia Moderna UNED

\section{CALAHORRA EN LOS TIEMPOS MODERNOS}

Calahorra constituye un caso particular dentro del panorama de los tiempos modernos en los reinos hispánicos. Pierde su importancia debido a la mayor pujanza de la relativamente nueva ciudad de Logroño, con una situación geográfica $-y$ un puente sobre el Ebro'- más favorable para beneficiarse del camino de Santiago, del tráfico económico regional y de las rutas hacia los puertos vascos. Pierde, asimismo, la residencia de sus obispos que habitualmente vivirán en Logroño durante el período. Conserva, empero, su catedral, y con ella un cabildo que controlaba el reparto del excusado, las tercias reales y el subsidio de cruzada de su diócesis. Ésta comprende el territorio actual de La Rioja salvo la comarca de Alfaro, la mayor parte de las provincias vascas $^{2}$, el arciprestazgo de Viana en Navarra, parte de la llamada riojilla burgalesa, Miranda de Ebro y el condado de Treviño en Burgos y zonas de Soria ${ }^{3}$.

Históricamente el obispado de Calahorra y La Calzada era una diócesis sufragánea de la Metropolitana de Zaragoza, extremo que cambia con la reordenación de obispados llevado a cabo por Gregorio X a ruegos de Felipe II en 1574. A partir de esta fecha, pasa a depender del nuevo metropolitano de Burgos. Esta nueva reordenación, bastante contestada, situaba aún más a Calahorra en la periferia de su propia diócesis.

\footnotetext{
1. Para ver la importancia del puente de Logroño en las rutas y comunicaciones del periodo y sus consecuencias en la evolución de la capital riojana, vid.: ZAMORA MENDOZA, J.:»El puente de piedra sobre el Ebro». Berceo, 1950, Núm. 14, y ÁlvAREZ ClaVIJO M. T.:»Aproximación a la evolución urbanística de la ciudad de Logroño (La Rioja): de la Edad Media al siglo XVIII». Berceo, 2001, Núm. 141.

2. Incluía el señorío de Vizcaya, casi integro, la totalidad de Álava y el arciprestazgo de Léniz en Guipúzcoa, vid SAINZ RIPA, E.: Sedes episcopales de La Rioja Siglos XVI-XVII, Vol. III. Logroño: 1996, Obispado de Calahorra y La Calzada-Logroño.

3. Ibíd.: Arciprestazgos de Yanguas y San Pedro Manrique.
} 
Los obispos, como decíamos, ya en tiempos medievales fijaron su residencia en Logroño, lo que constituyó un motivo de enfrentamiento con el cabildo que se sustanció en pleitos ${ }^{4}$ que se alarga durante todo el antiguo régimen. Contaron, para avalar su residencia en la actual capital riojana, con el apoyo de las provincias vascas, la ciudad y el clero de Logroño y con los argumentos de la mayor centralidad de Logroño en la diócesis, su mejor comunicación con los territorios vascongados y la falta de un lugar adecuado en Calahorra para establecer su residencia ${ }^{5}$. Enfrente, los cabildos de las dos catedrales de la diócesis, Calahorra y La Calzada, con el apoyo de sus respectivas ciudades y el de un argumento jurídico muy importante, la obligación establecida en Trento de que los prelados residieran en sus respectivas sedes episcopales. Sin embargo, y a pesar de las repetidas ordenes reales para que residieran en alguna de sus sedes, los obispos consiguieron con éxito resistirse a ello, salvando algunas estancias más o menos prolongadas.

\section{DEÁN Y CABILDO DE LA SANTA YGLESSIA CATEDRAL DE CALAHORRA}

Esta silla episcopal vacía, vel quasi, no significo una desaparición del poder y mecanismos de control que el capitulo catedralicio mantenía sobre los intereses de su diócesis. El derecho canónico estipula detalladamente cuales son las amplias competencias corresponden a los llamados beneficios mayores, básicamente los episcopales. No obstante el ejercicio de estas amplias competencias necesitaba del concurso del deán y cabildo para ser ejecutadas efectivamente y además se encontraban limitadas o eran complementarias de las propiamente capitulares ${ }^{6}$. En todo caso, la solución llegó de la mano del arbitrio tan habitual de la España de los Austrias: el recurso a la composición y al acuerdo. Aunque fueron frecuentes los pleitos entre obispo y cabildos tanto por el tema de la residencia, como por el derecho de los obispos a visitar canónicamente las catedrales, en general las relaciones transcurren por una, para ambas

4. Los pleitos a que dió lugar la residencia se encuentran básicamente agrupados en la signatura 3585 del Archivo Catedralicio y Diocesano de Calahorra (en adelante ACDC). También se encuentran referencias a los mismos en las colecciones de correspondencia de los obispos con el cabildo, legajos 2191, 2211, $2401,2537,2575,2655,2688,2784,2802,2817,2904,2939,3078,3445,3480,3717,4126$ у 4162 , y en los libros de actas capitulares, todas del ACDC. Una sucinta evolución del tema de la residencia de los obispos de Calahorra se encuentra muy bien tratado en: MATEOS GIL, A. J.: «El palacio episcopal de Calahorra». Berceo, 138, 2000.

5. En el siglo XVII se inician gestiones para la erección de una residencia acorde a la dignidad de su prelatura. Un primer intento se documenta en una carta del obispo Piñeiro de fecha 21/4/1644 en la cual se agradece el ofrecimiento de la casa del Chantre y de una huerta del arcediano de Berberíego para la construcción, ACDC 2655/7. El palacio finalmente se construye, junto a la Catedral en los terrenos de las casas donadas o adquiridas a dignidades del cabildo y que, a pesar de todo, no logró su propósito de fijar el domicilio del prelado en la ciudad calagurritana.

6. Un estudio muy amplio y en profundidad, que abarca el estudio de los mecanismos político-económicos de una diócesis similar en tamaño en el periodo estudiado es el de QuINTANA ANDRÉs, P. C.: «A Dios rogando, y con el mazo dando: fe, poder y jerarquía en la Iglesia canaria: (el Cabildo de la Catedral de Canarias entre 1483-1820)» Las Palmas de Gran Canaria: 2003, Ediciones del Cabildo de Gran Canaria. 
partes, necesaria colaboración en el ejercicio de los notables poderes y facultades que la Iglesia tenía depositados durante el antiguo régimen.

En el término de la Calahorra moderna se encontraban tres templos católicos. Las iglesias parroquiales unidas de Santiago y de San Andrés y la propia Santa Iglesia Catedral (en adelante SIC).Las principales dignidades ${ }^{7}$ de la SIC estaban compuestas por el deán ${ }^{8}$, los arcedianos de Calahorra o «urbano», de Vizcaya, Álava, Berberíego, Cameros y Najera a los que habría que sumar chantre, maestreescuela, canónigo doctoral y canónigo penitencial, como los mas señalados. El conjunto catedralicio se constituye en un autentico centro de poder político y administrativo. Se encontraba atendido por un nutrido grupo de servidores, a los que habría que sumar los clérigos de las parroquiales y los religiosos de los tres conventos de la ciudad ${ }^{9}$, que, con sus criados y personas subordinadas superarían largamente las quinientas ${ }^{10}$ personas dependientes económicamente de la Iglesia ${ }^{11}$, en un ciudad que en el XVII no debió nunca de superar las 4000 almas $^{12}$. Un grupo tan numeroso no podía, por tanto, dejar de ser tenido en cuenta por los sucesivos obispos y, además, suponía un centro de referencia político fundamental en la propia ciudad y muy a considerar en el extenso ámbito de la diócesis.

Las competencias a que hacíamos referencia son amplísimas desde el punto de vista económico. Las iglesias percibían, mediante los diezmos y primicias, una parte muy importante de la producción del territorio. Entre un tercio y un cuarto de ellos,

7. SAINZ RIPA, E., (op. cit.), Pág. 71.

8. Los deanes de Calahorra acumulaban también la dignidad de deanes de la catedral de La Calzada.

9. Franciscanos, carmelitas descalzos y religiosas carmelitas.

10. En un memorial de 1648, a propósito del calculo de las necesidades de manutención de la Catedral, se hace una relación de las personas que la integraban, ACDC: 2261/b8, según el cual:

"Compónese la Iglesia de ocho dignidades y 23 canonicatos que son 31 familias, a quatro personas por familia: la principal, un criado, una ama y una criada que son 124 personas ............................ 124.-

Más dieciocho racioneros a tres personas son................................................................................. 054.-

Más seis coadjutores a tres personas son ....................................................................................... 018.-

Más tres curas, quatro cuartos (racioneros), treinta capellanes, un sochantre, dos sacristanes, 4 ministriles, un secretario, dos porteros, 10 moços de choro, 12 açulejos (monaguillos con sotana azul), 2 campaneros, perrero y candelero que son 73 familias. A dos personas, una con otra, hacen 146

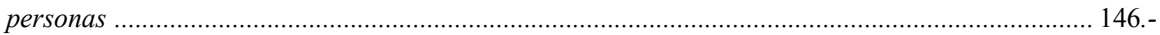
Que todas las dichas familias hacen 342 personas»

11. En 1753, las respuestas generales al Catastro de Ensenada arrojan una cifra de 110 clérigos (respuesta $\mathrm{n}^{\mathrm{o}} 38$ ) y 77 religiosos (respuesta $\mathrm{n}^{\text {o }} 39$ ), recogido en IBAÑEZ RODRÍGUEZ, S.: La ciudad de Calahorra en 1753. La averiguación del catastro de Ensenada: respuestas generales, títulos, certificaciones y vecindario. Calahorra: 2003, Amigos de la Historia de Calahorra.

12. Éstas son las cifras máximas que se pueden deducir de los vecindarios que rozaban los mil vecinos incluyendo los anejos y suponiendo una media de 4 almas por familia. También, aunque no se trata de un trabajo específicamente sobre Calahorra, se puede seguir la evolución demográfica de La Rioja Baja en el periodo, congruente con las cifras expresadas, en.: LÁZARO RUIZ, M y GURRÍA GARCÍA, P. A.: $L a$ crisis de mortalidad en la Rioja (siglos XVI-XVII). Logroño: 1989, Instituto de Estudios Riojanos. y en GuRRÍA GARCÍA, P. A.: La población de la Rioja durante el antiguo régimen demográfico. Logroño: 2004, Instituto de Estudios Riojanos. 
-prestamos o prestimonios-, eran destinados a los obispos y cabildos conjuntamente, que se repartieron según un acuerdo negociado en 1527 a partes iguales ${ }^{13}$, a esto habría que sumar las rentas percibidas por el importantísimo patrimonio en bienes raíces y los ingresos por bulas, oficios, etc. El Patronato Real estimaba la renta del obispo de Calahorra en 12.000 ducados $^{14}$, lo que sería equivalente a lo percibido por el cabildo. Otra función muy importante era la distribución de las contribuciones de la diócesis a la Real Hacienda, que se producía en su sede. Las tercias reales, el excusado, la bula de cruzada eran divididas entre los distintos arciprestazgos en la sala capitular de Calahorra.

Otro de los aspectos fundamentales de las funciones desempeñadas por obispo y cabildo conjuntamente eran los asuntos beneficiales. Aun excluidos los de patronato real y teniendo en cuenta la extensa tipología de los beneficios eclesiásticos en los siglos modernos, los cerca de 4.500 beneficios $^{15}$ documentados en el territorio eran en buena parte provistos y opositados ante los cabildos o bien designados directamente por él o el obispo, según las características de cada beneficio en particular.

El tercer aspecto en que la presencia de la iglesia se hacía sentir sobre sus coetáneos es el jurídico. Dejando a un lado el tema de la inquisición, que en el caso español no se puede definir propiamente como un tribunal de la iglesia stricto sensu, aun quedaban amplias parcelas sometidas a los tribunales eclesiásticos y al derecho canónico. Ello era debido a una jurisdicción especial, el llamado fuero eclesiástico, con la importante implicación de deber sustanciarse ante sus propios tribunales y conforme a su derecho, los asuntos que afectaran directamente o indirectamente a sus intereses.

El fuero eclesiástico afecta tanto a personas como a bienes, con lo que en principio cualquier asunto que afecte a unas o a otros se escapa de la jurisdicción de los tribunales civiles. Dada la elevada proporción de gentes de religión sobre el total de la población en el periodo y el peso de la Iglesia tanto en el crédito, como en la posesión de bienes raíces, un elevado número de pleitos debería sustanciarse ante sus tribunales. Tan es así, que se convierte prácticamente en una cláusula de estilo el incluir una renuncia al fuero en los censos librados contra religiosos, fábricas, cabildos y mesas capitulares. Por ejemplo, la escritura del censo de 4.000 ducados tomados por el Cabildo de la Catedral de don Antonio de Amador ${ }^{16}$. En ella se obligan las dos mesas del cabildo y los propios capitulares con sus personas y bienes a responder tanto del principal como de «...más todos los costos, daños y menoscabos, que en razón de lo referido se le siguieren ...», además «...renuncian al fuero eclesiástico, previa presen-

13. ACDC, libro de actas capitulares 1526-1529. Cabildo y obispo se reparten las parroquias en términos más o menos de equivalencia.

14. SAINZ RIPA, E., (op. cit.), Pág. 58, referido a mediados del s. XVI.

15. Vid. BARrio GoZALO, M.: «El sistema beneficial en la España del siglo XVIII. Pervivencias y cambios». Cuadernos Dieciochistas, $\mathrm{N}^{\circ}$ 2, 2001. El autor da una cifra de 4372 beneficios a la diócesis calagurritana. Este trabajo es una aproximación amplia y muy interesante a las características y tipología del sistema beneficial moderno en España.

16. ACDC: $27 / 409 / 40$. 
tación de la escritura a los jueces y justicias de su Santidad...», lo que constituye una condición muy lógica a exigir por el acreedor en garantía del buen fin de la operación, por el elevado riesgo que supondría dejar la tutela judicial de la misma a los tribunales eclesiásticos, esto es, a la otra parte de la operación.

Así y en virtud del fuero especial los tribunales diocesanos atendían tanto en temas de jurisdicción civil como criminal $^{17}$. Sus resoluciones eran apelables en sede metropolitana, en Burgos, y las sentencias de ella, lo eran a su vez ante la nunciatura, pudiendo, en caso que la voluntad y recursos de las partes lo permitieran, acudir a la Santa Sede en demanda de una resolución más favorable a sus intereses.

Se conforma así un estatuto legal privilegiado y con importantes mecanismos coercitivos que pueden llegar incluso contra oficiales del reino y autoridades, como se verá en el siguiente caso, descrito en una carta del obispo Esparza al deán de Calahorra ${ }^{18}$ «Habiendo recivido la carta de V. S. de 15 del corriente, mandé se viesen los autos que remití a el Vicario y, reconociendo por ellos el desacato que an cometido el alcalde y sus ministros de la villa de Genevilla contra la jurisdicción que en nuestro nombre ejerce el vicario, ordené fuesen los ministros necesarios para que entregasen el trigo y trajessen pressos al alcalde y demás ministros y olgare se consiga sin ningún embarazo para que V. S. sea servido y la jurisdicción respetada como es razón. Dios Guarde a V. S. felices años en su mayor grandeza dándome muchos empleos de su servicio. Logroño y octubre 19 de 1683. Gab. Obpo. de Calahorra y la Calzada».

Además de lo anterior la Iglesia gozaba de una jurisdicción plena en una clase de asuntos bien definidos: los matrimoniales. Resulta bastante lógico que, con una población oficialmente católica al 100\%, sea competente para entender los asuntos la única competente para celebrar y extinguir los matrimonios, institución sacramental, al fin y al cabo. Separaciones, dispensas por parentesco, amonestaciones, demandas por malos tratos conyugales eran tratados en ella y constituyen un volumen muy significativo de los documentos custodiados en los archivos eclesiásticos.

Esta competencia jurisdiccional de la iglesia tenía incluso componentes legislativos y de policía sobre los más diversos aspectos como lo demuestra el siguiente fragmento de una carta dirigida al cabildo, «...lo profano de los traxes que usan todo genero de mugeres, motivando muchos pecados, por sus escandalosos escotes, nos han obligado a publicar el edicto que remito a $V S^{a}$, para que nos ayude a reformar el exceso tan peligroso para las almas. ${ }^{19}$

Estas atribuciones jurisdiccionales, necesariamente, involucraban al cabildo diocesano en su gestión, formando parte de los distintos tribunales, ejecutando sus sentencias, edictos y disposiciones, promoviendo causas y litigios ante ellos y, por último, viendo y fallando en los procedimientos en que era competente.

17. Las causas criminales vistas ante los tribunales de la Iglesia comprendían los delitos cometidos por y contra clérigos, en recintos religiosos y algunos delitos perseguidos de oficio por los fiscales del obispado como los amancebamientos y/o las relaciones extramatrimoniales.

18. ACDC: 2939/35.

19. Carta del obispo Esparza al deán y cabildo de 16 de Febrero de 1672, ACDC, signatura 2939/17. 
En resumen, un amplio abanico de asuntos era tratado, gestionado o pertenecía a la esfera de atribuciones de la Iglesia y de sus dignidades territoriales. Obviando el componente espiritual, se trata en esencia de un órgano más de la administración de la monarquía. Cada obispo de Calahorra-La Calzada era presentado por el rey y miembro nato del consejo de su majestad. Las competencias administrativas fiscales y judiciales ejercidas son, claramente, pertenecientes a las actuales de los estados contemporáneos $\mathrm{y}$, por tanto, debemos entender a la Iglesia como situada en el entramado institucional de los estados modernos como un órgano político más y no el menos importante de ellos.

Debemos señalar que esta característica de órgano de poder político y económico que hemos visto posee la Iglesia, forzosamente debería de provocar las apetencias de grupos sociales interesados en aquel. Todo ello en un contexto temporal en el que está plenamente documentado el acceso a posiciones de poder mediante estrategias familiares bien definidas, como la compra de cargos hereditarios y la obtención de beneficios económicos a través de los mismos o del arrendamiento de tributos y rentas.

\section{CONCEJO, JUSTICIA, REGIDORES, CABALLEROS, ESCUDEROS, OFICIALES Y HOMBRES BUENOS DE LA CIUDAD DE CALAHORRA}

A la cabeza de la estructura política local de Calahorra habría que situar al corregidor de la ciudad, que lo era también de Logroño y Alfaro y ostentaba el titulo de Capitán General de las Fronteras del reino de Navarra. Su residencia habitual era, al igual que en el caso del obispo, la ciudad de Logroño, con lo que las relaciones con las autoridades locales eran ocasionales y habitualmente se producía la delegación en la figura del alcalde mayor de sus importantes atribuciones civiles, fiscales y jurisdiccionales. Otra de sus competencias era el ordenar el reclutamiento de levas. Aunque Calahorra gozaba del privilegio de exención de participar en las milicias ${ }^{20}$, tenía obligación de servir con una compañía de 100 hombres para defender el Reino de Navarra. En el s. XVII re realizaron cuatro reclutas de soldados en los años de 1644, 1655, 1667 y $1668^{21}$, siendo las tres primeras levas forzosas de naturales y la última una recluta de voluntarios con cargo a la Hacienda Real.

Calahorra conserva su estatuto de realengo durante todo el antiguo régimen, por lo que todos los vecinos formaban el concejo de la ciudad y constituían, al menos teóricamente, el poder municipal ciudadano. Decimos que teóricamente, ya que la costumbre del concejo abierto fue perdiendo importancia y vigencia conforme se desarrolla el siglo XVII, surgiendo en su lugar una monopolización de los cargos municipales por

20. Vid. SAmaniego Martí, C.: El servicio de milicias en el siglo XVII: Un privilegio de exención en Logroño, Calahorra y Alfaro. Actas del Segundo Coloquio sobre Historia de La Rioja. Logroño, 1986, Vol. 2, 1986, Págs. 225-236.

21. Año 1644: AHMC (Archivo Histórico Municipal de Calahorra): 458002, serie 2.1.5.2; 1655: AHMC, signatura 458003, serie 2.1.5.2;1667: AHMC, signatura 458005, serie 2.1.5.2; 1668: AHMC, signatura 458007, serie 2.1.5.2. 
una emergente oligarquía municipal ${ }^{22}$ articulada en torno a unas pocas familias calagurritanas. Esto constituye un proceso paulatino en el que intervienen diversos factores.

Ya desde tiempos bajo-medievales la organización institucional de las ciudades riojanas difiere de la habitual en las ciudades del resto de la corona de Castilla, siendo más próxima a la forma de organización de los municipios vascongados. En ambos casos existe una elección anual de los oficios municipales que se diferencia de la posesión vitalicia, e incluso hereditaria, de los cargos municipales en Castilla ${ }^{23}$. La figura central del sistema eran los regidores, elegidos anualmente a mitades entre los representantes de los hidalgos y los de los hombres buenos. Sus competencias eran la administración de propios y rentas, abastos, regulación de precios y salarios, obras públicas, tareas asistenciales, el control de la recaudación de impuestos y la elección de los oficios municipales. Las elecciones de los cargos y oficios municipales se celebraban cada uno de enero en la sala capitular de la SIC, lo que irá explicado más adelante.

Sin embargo, a partir de Felipe II se extiende a Calahorra la práctica de la venta de oficios por parte de la corona con lo que, a principios del siglo XVII, había 14 regimientos perpetuos en la ciudad. En 1603, la ciudad procede al consumo de los regimientos mediante un pago al rey de 14.000 ducados, para lo que tuvo que endeudarse fuertemente y comprometer su situación financiera durante largo tiempo ${ }^{24}$. Gracias a esto la ciudad pudo retornar a su costumbre de elección anual de los oficios municipales. A pesar de ello, y olvidando los privilegios emitidos por la corona, Felipe IV vuelve a vender regimientos de Calahorra a partir de 1629, incluyendo también los cargos de alguacil mayor y el de escribano mayor, con el lógico disgusto de los ciudadanos quienes se quejaban de las arbitrariedades y comportamiento de los regidores perpetuos respecto de los asuntos de la ciudad y de las mayores cargas sufridas por el resto de ciudadanos por culpa de aquellos. Estos sucesos desembocan en los motines y tumultos de 1648 y en un nuevo consumo de los regimientos perpetuos de la ciudad para lo que solicitaron el auxilio del cabildo de la SIC y de las parroquiales, quienes contribuyeron con 4000 ducados $^{25}$ destinados al consumo de cuatro regimientos.

Los salarios cobrados por los regidores calagurritanos, inferiores a los ocho ducados al año, difícilmente justificarían los desembolsos practicados en la compra de los mismos. Las compensaciones vendrían por el prestigio obtenido por el desempeño de estos cargos y muy probablemente por las posibilidades de enriquecimiento que depararan las oportunidades de negocio surgidos al calor del desempeño del poder municipal. Así las acusaciones contra la gestión del pósito, sobre la calidad y la procedencia

22. Para consultar la estructura, composición, competencias, instituciones e historia del poder municipal calagurritano, vid. GARCía CALONGE, M.: El poder municipal de Calahorra en el siglo XVII. Aspectos institucionales. Calahorra: 1998, Amigos de la Historia de Calahorra.

23. Vid. Diago Hernando, H.: El concejo de Calahorra durante el reinado de los Reyes Católicos, aspectos de su organización institucional. Berceo, 144. Logroño, 2003.

24. García CALONGe, M. (op. cit.), Págs. 55-66, la autora cuenta detalladamente la evolución de la venta de los regimientos perpetuos y sus consecuencias para la ciudad.

25. ACDC: libro de Actas capitulares 131, 2 de Enero de 1652. 
de los géneros que se vendían en la carnicería municipal o el desigual reparto de las contribuciones nos proporcionan pistas sobre en que lugares y de que forma lograban estos personajes rentabilizar su actividad.

Se produce un proceso de concentración de los oficios municipales en unas pocas familias. Estas acceden a los mismos mediante la compra de cargos en algunos casos o gracias a la presencia en los órganos decisorios por razón de la creación de una tupida e inextricable red de intereses y alianzas familiares. Los apellidos Díaz de Esparza, García de Jalón, Gómez Carrero, Gualite, López de Murillas, Lacanal, Paniagua, Paredes o Velasco prácticamente monopolizan todas las elecciones de oficios importantes en una evolución que se acentúa a medida que progresa y finaliza el siglo XVII.

\section{RELACIONES CONCEJO-CABILDO CATEDRALICIO. DISCORDIAS, CONCORDIAS, INFLUENCIAS E INTERFERENCIAS}

Los motivos de enfrentamiento entre las dos instituciones de poder político tuvieron esencialmente una motivación económica y quizás el más significativo de los mismos fuera el relativo a la carnicería de la Catedral. Ésta, obviamente, perjudicaba los intereses directos que regimiento y regidores tenían en la distribución de la carne a través de la municipal, en la comercialización de sus propios géneros y en el cobro de los impuestos que la venta de la carne generaba. A raíz de una denuncia de los regidores, el obispo Piñeiro escribe al deán y cabildo haciéndoles traslado de las quejas de la ciudad: "Al consejo de su majestad se le ha hecho relación de que muchos vecinos seglares, deudos y amigos de los prebendados de nuestra Sta. Iglesia gastan de su carnicería, defraudando los derechos que se deben a su magestad por ese camino. $Y$ el sr. Camporredondo, en su nombre, me escribe la inclusa para que ponga remedio, si en éste hubiere algún exceso, y aunque entiendo que, por la competencia de esa Santa Iglesia con la ciudad, pueden ser menos verdaderos los informes, pues respecto de dar fiada la carne, tanto tiempo como ay se acostumbra se ve que solamente se dará a los prebendados de quienes se podrá cobrar en las cedulas de las rentas que les tocan. Con todo eso, por cumplir con mi obligación, no puedo dexar de les presentar a V.S. quanto debe cuydar que, a este titulo, no se vea menoscabada la Real Hacienda, pues demás que en todos tiempos es materia de tanto escrúpulo, en los presentes debemos tener toda atención, por los grandes gastos que su magestad tiene sustentando tantos exércitos en defensa de Nra. Fe y desta monarchía y especialmente debemos atender más a esta causa los que estamos tan vezinos al exército enemigo, pues con la asistencia de su magestad en Zaragoza y disposición de sus armas detiene a los enemigos para que no entren por nuestras cassas y perturben la quietud de que gozamos. Suplico a V. S. mire esto con el desvelo que pide causa tan justa, pues aunque ella no estuviere de por medio, por Nra. Reputación lo deviéramos hazer, para que no tuvieran los seglares el menor motivo de quexa en la administración de lo que nos toca, para que faltando el clamor dellos, quede más fortalecido el derecho de tener las carnicerías 
que en tiempos tales, si se continúan las quexas, pueden obligar al Consejo a tomar diferente resolución.... ${ }^{26}$

El 2 de mayo de 1644 en carta dirigida al obispo ${ }^{27}$, en contestación a la epístola anterior, el deán responde a las quejas de la ciudad referidas «Ahora nuevo se quexan de que aún duran los excesos, por que, con esta ocasión, muchos vecinos, por el deudo o amistad que tienen con los prebendados, cometen fraudes contra la hacienda de su magestad, llevando carne de la carnicería de la Iglesia y dexando de llevar la de la ciudad, con que el medio que se tenía por efectivo para satisfacer a su magestad la cantidad que se le resta debiendo de los millones, dexa de serlo cessando el gasto de la carnicería de la ciudad.» El cabildo niega las denuncias de la ciudad de una forma muy eficaz. En primer lugar afirma que la contabilidad de la carnicería es clara y sus libros, que registran todas las operaciones, no permiten el fraude. No obstante lo anterior, al conocer las quejas de la ciudad, la mesa capitular ha dado instrucciones a sus mayordomos para que no se toleren excesos «so pena de grandes penas». Por último ofrecen argumentos para explicar la bajada del consumo de la carnicería de la ciudad: «...estas quiebras de las alcabalas y millones, otras caussas tienen que decir muy diferentes. Una de ellas es notoria la pobreza de la mayor parte de los vecinos de la ciudad, de que V. Ilma. es buen testigo, pues la ha tocado con las manos al tiempo que ha estado en ella, acudiendo a remediarla. Desta mayor parte de los vecinos es certísimo que tendrán a buena suerte el tener con que comprar pan, sin hechar de menos la carne de la carnicería. Otras caussas que señalan destas quiebras que miran al modo del gobierno de la ciudad, ni a nosotros nos toca el averiguarlas, porque la experiencia nos ha enseñado que los eclesiásticos no somos bien oídos en queriendo censurar el modo de gobierno de los seglares della, ni deseamos saber del dicho gobierno, sino del de la Ntra. Iglesia, solo queríamos que nos dexasen ni acordarse de nosotros y no podemos conseguirlo».

A vuelta de $\operatorname{carta}^{28}$ el obispo Piñeiro, agradece al deán y cabildo sus razones, que atiende y comunica que da traslado de ellas al consejo. La carnicería permaneció abierta hasta bien entrado el siglo XIX.

Otro de los litigios que enfrentaron periódicamente a las autoridades civiles y eclesiásticas de Calahorra es el relativo al privilegio inmemorial que tenían los capitulares de importar libremente géneros del reino de Navarra. Esta antigua prerrogativa, que arranca de tiempos anteriores a la unión política de los territorios de la diócesis, tenía como propósito el facilitar a los sacerdotes calagurritanos el consumo de mercancías navarras con la excepción del cacao, azúcar y chocolate. Esto obviamente no agradaba a los oficiales reales y arrendadores de los derechos de portazgo lo que se sustanció en diversos pleitos litigados en contradictorio entre el fiscal del reino y el deán y cabildo de la catedral. No obstante se logró ver confirmado el privilegio en diversas ocasiones:

26. Ibíd. 2655/8. Carta de 25/IV/1644.

27. Ibíd. 2655/9.

28. Ibíd.: 2655/10. 
real instrucción ejecutiva de 1619 y confirmación por Carlos II en 16 de septiembre de $1673^{29}$. Todavía en 1743 el Ministro de Hacienda, Joseph del Campillo ordena ${ }^{30}$ la exención de todo privilegio por este asunto, a lo que la catedral se opone, iniciándose otro litigio una vez más ganado por los capitulares.

Pastos, ganados, regadíos, diezmos, numerosos fueron los motivos de discordia $\mathrm{y}$, normalmente, en todas las ocasiones el cabildo suele salir victorioso en sus enfrentamientos con el regimiento calagurritano dirimidos ante las instituciones centrales de la monarquía. La mayor entidad política de la Iglesia, sus mejores recursos a la hora de enfrentar pleitos y la importancia de sus contribuciones a la Hacienda Real le pronosticaban un mejor resultado en los mismos. Aquellos, habitualmente, se sustanciaron en la confirmación de sus privilegios frente al celo de las autoridades civiles que se resistían tenazmente a los mismos. En real provisión de 4 de noviembre de 1678, dada por mano del rey por Diego de Urueña Navamuel, secretario de cámara del rey, se instruye al alcalde mayor de Calahorra para que no impida pasar los granos de los eclesiásticos ${ }^{31}:$ «Se prohibe tomar ni embargar los granos que hubiere menester para el gasto de sus personas, cassas y familias y para dar las limosnas competentes, según su calidad, estado y obligación y ansimissmo no se impida sacar los frutos de un lugar a otro» y continua, unos párrafos adelante, "que de aquí en adelante por el tiempo que durare esta concordia no se ha de poder tomar ni embargar pan alguno de los eclesiásticos asi de trigo, cevada u otras semillas, aunque sea para probeer harmadas, exércitos, fronteras o pósitos de los lugares, ni para sembrar los labradores, ni ningún pretexto, causa ni razón, aunque se pague a cualesquier precios, no siendo casso de hambre o necesidad pública que sea notoria y tal que inste el remedio del sustento. $\mathrm{Ni}$ entonces se ha de tomar el pan de los eclesiásticos sin tomar primero el de los seglares».Tan favorable trato ilustra muy eficazmente la posición de privilegio que disfrutó el estamento eclesial durante los siglos modernos.

Otro ejemplo muy peculiar resulta de la lectura de la carta que el Obispo Gonzalo Chacón y Velasco, remite al deán, pocos días después de promulgar un edicto ${ }^{32}: \ll L a$ causa que me movió a promulgar las censuras acerca del premio de la plata que se an publicado fue el aver tenido carta del Sr. Presidente de Castilla, escrita por mano de su magestad, en que me daba quenta de la nueva premáttica que en esta razón avía salido y que, por que no tuviera falencia por mano de los eclesiásticos y todos generalmente la guardasen y los seglares no se aprovechasen dellos para por su mano hacer los dichos trueques excediendo de lo lícito, me pedía y mandaba su magestad promulgase dichas censuras en este obispado prohibiendo lo susodicho, pues en ello excusaría algunos rigores de que el consejo hacía demostración, como en el mandamiento refiero, pero mi intención no fue más de prohibir que no se entrometan los clérigos a ser corredores

29. Ibíd.: 27/410/7.

30. Ibíd.: 2293/28.

31. Ibíd.: 2297/21.

32. Ibíd.: 2575/6. 
en los trueques de los seglares pero no que, si ellos an menester la plata y quieren dar por el premio todo lo que quisiesen, no lo puedan dar, no hallándola menos y asi vuestras mercedes podrán tomar toda la que quisiesen y ubiesen menester, al precio que la hallaren, sin por ello incurrir en pena ni censura alguna, pues quando claramente lo prohibiera, de muy buena gana lo dispensaría con vuestras mercedes, por lo mucho que les estimo y cuyas vidas deseo guarde Dios muchos años, como puede. Logroño y Junio 22 de 1633. Gonzalo, obispo de Calahorra y la Calzada». Como poco, resulta curiosa la forma de acatar las órdenes reales, promulgando censuras en su obediencia, para, inmediatamente, convertirlas en papel mojado mediante una misiva que disculpa su cumplimiento con unos criterios tan amplios que, dada la importancia financiera de las operaciones que realizaban los clérigos, difícilmente dejarían de tener su repercusión en el tipo de cambio general, para el que no cabrían compartimientos estancos. Evidencian las letras del Sr. Obispo la sutileza, cintura y brillantez política que resultan tan características de la forma de actuar de la Iglesia Católica.

Sin embargo, la dinámica de las relaciones entre municipio e iglesia no llega a hacer crisis, atemperada por el elemento tan característico, como decíamos, de la España de los austrias: el pactismo y el recurso a la negociación. Reforzado, además, por las sugerencias en tal sentido que llegaban en forma de epístola episcopal. Como muestra, valga la carta que en agosto de 1650 dirige el obispo Juan Joaniz de Echalar al deán y cabildo de la SIC: «Ya tiene experiencia $V$. S. de mi aborrecimiento a pleytos y lo mucho que amo la paz, y así, cuando supe el que se había comenzado entre V. S. y la ciudad, lo sentí mucho, que, aunque este pleyto no es de mucha consideración, temo no resulten de otros que lo sean y ocasión de enemistades y disgustos encendiendo algún fuego que luego no sea fácil de atajar y, pues ahora se puede ocurrir a este inconveniente será mejor que después, quando, aunque se quiera, no sea posible. Siempre ha conservado $V$. S. con la ciudad mucha paz y no es razón faltar a ella ahora y para que esta se conserve, sería bueno el tratar de alguna composición y que, para ella, nombrase $V$. S. comisarios que la tratasen, que yo sé que la ciudad no quiere pleytos con $V$. S. a quien suplico trate de componer este negocio» ${ }^{33}$. Más clara no puede estar la intención del obispo Joaniz de intentar evitar en lo posible los conflictos abiertos con las autoridades civiles. Dos años más tarde, en enero de 1652, vuelve a escribir en términos parecidos: «Mucho me pesa que los enconos y pleytos de esa ciudad y el estado eclesiástico della pasen tan adelante sin haber bastado mi autoridad a componerlos, y que los regidores menosprecien las censuras eclesiásticas, tan en daño de su alma, deben ser mal aconsejados, pues de cristianos solo esa causa podemos presumir. Dios quiera que reconozcan no tienen razón para que aya paz cuia falta me llega muy al alma; y el nuevo pleyto que $V$. S. tienen sobre el pasto de su ganado. Enbio esas dos cartas con deseo de que surtan efecto y enviará la de don Antonio de Riaño a tener con el algún conozimiento, y, en todo lo que yo valiere me tendrá $V$. S. muy a su servicio,

33. Ibíd.: 2688/14. 
reconociendo mis obligaciones.» ${ }^{34}$ En esta ocasión, como vemos, interviene e incluso ofrece su intervención personal para solucionar los conflictos con la ciudad.

Esta política se sustancia en concordias frecuentes como la recogida en el siguiente fragmento ${ }^{35}$ : «En la conferencia que hemos hecho, emos ajustado lo siguiente: que la Santa Iglesia, usando de la çedula o probisión que tiene a su favor, requiera con ella, a la justicia secular y pida su cumplimiento y que el alcalde mayor ponga su respuesta en forma y con lo que respondiere y consultare, de el ilustrísimo señor obispo se remita lo uno y lo otro, con propio que se haga, por ambas comunidades, a el Real Consejo, en manos de su secretario de cámara más antiguo o a el que tocare. Y la decisión que hiciese el Real Consejo a esta respuesta y consulta sea de observar y estar y pasar por ambas comunidades y, en el ínterin, se estén las cosas de este pleyto en el estado en que están y en ellas no sea de inobar por ninguna de las partes y su ilustrísima a de suspender los tiempos y censuras y el de la real probisión, asta en tanto que venga la resolución dicha; sin que sea visto correr tiempo hasta oy, porque asi lo consienten ambas partes y lo firmaron en la ciudad de Calahorra a cinco de septiembre de 1650 años. Don Juan Cantero Figueroa, licenciado Andrés de Victoriaza, don Pedro de Ontiveros, don Pedro de Medrano, Joseph de Arieta».

Podemos ya, por tanto, resumir las pautas de la Iglesia en sus pugnas con las autoridades y grupos de poder municipal: intentar evitar los conflictos directos, llegado el caso recurrir a la transacción y, si ello no fuere posible, al arbitraje o decisión de un tercero, la autoridad central. El principio director de esta política es que, «rebus sic stantibus», la situación es favorable a sus intereses por lo que conviene evitar cualquier enfrentamiento que pueda originar cambios en la misma. Naturalmente este no debió de ser el punto de vista de los grupos que se veían perjudicados en sus intereses y que, seguramente, desearían participar en los importantes intereses y en el poder político detentado por la Iglesia, intentando una penetración en su estructura y en sus órganos rectores.

\section{CAPELLANÍAS}

Las capellanías de misas surgen a finales del medievo como un ingenioso mecanismo financiero para lograr acortar la estancia de las ánimas de sus fundadores en el purgatorio $^{36}$. Consistían en la imposición de un capital en instrumentos financieros o

34. Ibíd.: 2688/19.

35. Ibíd.: 2297/17, «acuerdo entre el cabildo y la justicia secular para acabar en sus pleitos ambas comunidades».

36. El catecismo de la Iglesia católica recoge el purgatorio en su parte primera, sección segunda, capítulo tercero, en los párrafos: 1030 «Los que mueren en la gracia y en la amistad de Dios, pero imperfectamente purificados, aunque están seguros de su eterna salvación, sufren después de su muerte una purificación, a fin de obtener la santidad necesaria para entrar en la alegría del cielo» y 1031 «La Iglesia llama Purgatorio a esta purificación final de los elegidos que es completamente distinta del castigo de los condenados. La Iglesia ha formulado la doctrina de la fe relativa al Purgatorio sobre todo en los Concilios de Florencia (cf. DS 1304) y de Trento (cf. DS 1820: 1580)». 
bienes raíces. Dicho patrimonio se invertía o arrendaba, constituyéndose los réditos en una renta del capellán quien, a cambio, se comprometía a celebrar una serie de misas en favor del ánima del fundador. El capital inicial quedaba sujeto al cuidado de un patrono, nombrado, al igual que los capellanes, según las detalladas reglas establecidas en el instrumento de fundación y que normalmente eran familiares o descendientes del fundador. Uno de los derechos usualmente anejos al de patronazgo es el de presentación de los capellanes ${ }^{37}$.

Las capellanías podían ser o laicales o colativas. Las laicales eran aquellas que dependían de la justicia civil y daban una mayor libertad en su constitución y administración. Las colativas o eclesiales se caracterizaban por que la titularidad de los bienes pasaba a ser propiedad de la Iglesia, si bien sujetos a la dotación estipulada, y dependían del ordinario del lugar, quien normalmente delegaba en un juez de capellanías. En este caso además se sometían a un procedimiento estrictamente reglado en cuanto a su constitución, provisión, funcionamiento, eventual reinversión de capitales y a visitas periódicas por parte de la autoridad eclesiástica. En contraprestación a la menor libertad, éstas proporcionaban una mayor seguridad a los fundadores y se beneficiaban del favorable régimen jurídico de los bienes de la Iglesia. Como rasgo fundamental de la institución, las capellanías colativas establecen lo que podemos definir como un beneficio eclesiástico impropio (ya que estan constituidos sobre un patrimonio privado) y simple (no llevan aneja cura de almas) a título del cual es posible tomar las órdenes $\operatorname{sagradas}^{38}$.

37. Para ampliar el concepto, contenido y significado de las fundaciones capellanícias existe una amplia producción historiográfica, señalamos los siguientes trabajos por su interés: CASTRO PEREZ, C., CALVO CruZ, M. y GranAdo SuAREZ, S: «Las capellanías en los siglos XVII-XVIII a través del estudio de su escritura de fundación» en Anuario de Historia de la Iglesia, XVI; Pro RUIZ, J: «Las capellanías: familia, iglesia y propiedad en el Antiguo Régimen», en Hispania Sacra, año 41; VON WOBESER HOEPNER, G: «La función social y económica de las capellanías de misas en la Nueva España en el siglo XVIII.», Revista Estudios de Historia Novohispana, vol. XVI.

38. Para ordenaciones a titulo de patrimonio ver, por ejemplo, GolmaYo, P. B. Instituciones de Derecho Canónico. Madrid: Librería de Gabriel Sánchez, 1896. Capitulo XXX, epígrafe 378. «La excepción del concilio de Letrán dio ocasión a que se introdujese el patrimonio como título para recibir las órdenes sagradas, porque los obispos continuaron ordenando sin beneficio y sin incurrir tampoco en la sanción penal, toda vez que los ordenados tuviesen bienes con que sostenerse. Como esto proporcionaba ventajas a los ordenados y a la Iglesia, lo que principió por un abuso llegó a ser un acto legal después que las decretales lo admitieron como verdadero título de ordenación. Esta facultad ilimitada de ordenar a los que tuviesen bienes patrimoniales, traía también sus inconvenientes si llegaba a ser excesivo el número de los ordenados, o no se adscribian a una iglesia para ejercer en ella su ministerio. Para atender a estos dos extremos mandó el concilio de Trento que los obispos no pudieran ordenar a título de patrimonio, si no lo exigiese la necesidad o comodidad de las iglesias, y que nadie se ordenase en adelante sin adscribirse a aquélla por cuya necesidad o utilidad había sido ordenado. Para que no degenere en abuso este título extraordinario de ordenación, ha de preceder la formación de un expediente en el cual conste la necesidad o utilidad de la iglesia, y la erección del patrimonio conforme al espíritu de los cánones; y por lo que hace a España, con arreglo a los concordatos y disposiciones particulares. (...) El espíritu de los cánones en cuanto al título de ordenación ha sido siempre que los clérigos tuviesen la renta necesaria perpetuamente para su congrua sustentación, a fin de evitar en ellos la mendicidad, o 
Los tiempos barrocos, con su religiosidad teatral y formalista, fueron tiempos favorables para la proliferación de estas fundaciones. Perfectamente encajados en el universo mental y el contexto cultural de sus contemporáneos ofrecían tanto un mecanismo de redención post mortem como una posibilidad de perdurar en la memoria de los vivos.

Hasta aquí y situándonos en una visión antropológica, se ha descrito lo que pudiéramos llamar la versión «emic» del fenómeno ${ }^{39}$. Para abordar una versión «etic» debemos intentar una aproximación necesariamente más compleja, como complejo es el fenómeno de las capellanías.

Desde un punto de vista meramente patrimonial, resulta evidente el pensar en las ventajas fiscales y de régimen jurídico que la fundación de capellanías aporta a los patrimonios familiares que optan por este sistema de vinculación. De una parte la nula fiscalidad de unos bienes que, de iure, pasan a ser propiedad de la iglesia, presentan ventajas de rentabilidad respecto a la transmisión directa de los bienes patrimoniales a los herederos de una forma sucesiva. La inembargabilidad, la imprescriptibilidad y la inalienabilidad de la que disfrutan estos bienes garantizan además la continuidad del goce de los bienes durante generaciones ${ }^{40}$.

Sin embargo existe otro extremo en el que puede cobrar sentido la utilidad de la institución de capellanías, visto desde la óptica del presente estudio, que es la de analizar los mecanismos de relación entre instituciones políticas civiles y religiosas. Efectivamente, mediante la erección de una capellanía colativa se constituye un beneficio eclesiástico a título del cual es posible, y frecuente, ordenarse...

que se dedicasen a oficios indecorosos. La congrua sustentación iba unida al principio a la ordenación y adscripción a una iglesia; después a la colación de un beneficio. El patrimonio, por consiguiente, ha de tener, conforme a esta doctrina, las cualidades siguientes: $1{ }^{a}$, el carácter de perpetuidad; 2. ${ }^{a}$, ha de ser poseido pacificamente; 3. ${ }^{a}$, ha de consistir en bienes determinados, inmuebles o raices; $4 .^{a}$, no ha de poder enajenarse, a no ser que hubiese obtenido algún beneficio, o de otra manera cierta, a juicio del obispo, pudiera atender a su subsistencia; 5. ${ }^{a}$ y última, no ha de haber en su erección perjuicio de tercero, lo cual sucedería si el padre, por ejemplo, desatendiese a sus hijos privándoles de su legítima para formar a uno de ellos el título de ordenación.»

39. HARris, M.: Antropología cultural. Madrid: 1997, Alianza editorial. El autor hizo frecuente el uso, dentro de las ciencias sociales, de los términos emic y etic, tomados de fonología y fonética, respectivamente. Harris sostiene que existen elementos de una sociedad que no se perciben a simple vista, pero condicionan decisivamente la vida de la misma, aunque los afectados no sean conscientes de ello, Harris las explica recurriendo a la causalidad infraestructural o etic. Las justificaciones que los propios afectados dan son lo fenoménico, lo que el observador puede ver, es decir lo emic. Marvin Harris es creador de la estrategia de investigación conocida como materialismo cultural. Su trabajo explica la formación de instituciones sociales combinando las teorías de Thomas Malthus sobre la influencia del crecimiento de la población con las de Karl Marx acerca del efecto de los medios de producción.

40. Dado el caso de que un heredero del fundador quedase, por ejemplo, sujeto a un procedimiento concursal, los bienes de la capellanía quedarían exentos e íntegros para beneficiar a la siguiente generación de familiares. 


\section{LAS CAPELLANÍAS COMO FORMA DE PENETRACIÓN EN LOS MECANISMOS POLÍTICO-ECLESIALES}

Por los ejemplos ya vistos anteriormente vemos que los grupos privilegiados de Calahorra debían de estar lógicamente interesados en ganar capacidad de influencia en una institución que, con relativa frecuencia, interfería en sus intereses y que además constituía un formidable resorte de poder en su contexto temporal.

También, y desde un punto de vista de rentabilidad económica, puede resultar muy interesante el acceder a posiciones de privilegio en los órganos de decisión de la Iglesia. La explotación de sus bienes raíces, la intervención en sus operaciones financieras, el arrendamiento de rentas y frutos ${ }^{41}$, las operaciones de préstamo a sus fábricas, ofrecen buenas oportunidades de obtener beneficios y una razonable seguridad en el buen fin de las operaciones.

Como ejemplo de la importancia que podrían tener estas operaciones véase el siguiente cuadro que recoge las magnitudes que importaban las rentas arrendadas de la diócesis a mediados del XVII:

Renta del obispado, frutos del $1647^{42}$

\begin{tabular}{|l|r|l|r|}
\hline \multicolumn{1}{|c|}{ Parroquia } & \multicolumn{1}{|c|}{$\begin{array}{c}\text { Renta en } \\
\text { reales }\end{array}$} & \multicolumn{1}{|c|}{ Parroquia } & $\begin{array}{c}\text { Renta en } \\
\text { reales }\end{array}$ \\
\hline Colegial de Logroño & $1.400 .-$ & Briones y Rodezno & $6.600 .-$ \\
\hline Sanctiago de Logroño & $6.650 .-$ & Ullauri, Ximilio y Baños de Rioja & $1.650 .-$ \\
\hline San Bartolomé de Logroño & $500 .-$ & Yanguas y San Pedro & $32.000 .-$ \\
\hline Murillo de Leça & $6.600 .-$ & Ynestrillas, diezmos y renta fixa. & $2.000 .-$ \\
\hline Ribafrecha & $6.600 .-$ & Lumbreras & $3.000 .-$ \\
\hline Ocón & $17.000 .-$ & Laguna de Cameros & $1.500 .-$ \\
\hline Nalda y Çorçano & $4.600 .-$ & $\begin{array}{l}\text { Muro, Ornillos, Velilla y } \\
\text { Baldosera }\end{array}$ & $2.800 .-$ \\
\hline Sotes & $550 .-$ & Axamil y Ravanera & $1.400 .-$ \\
\hline Uruñuela y Somalo & $400 .-$ & Enciso & $5.200 .-$ \\
\hline Huercanos & $2.800 .-$ & $\begin{array}{l}\text { Arnedillo y Munilla, todo } \\
\text { diezmos y renta. }\end{array}$ & $4.300 .-$ \\
\hline
\end{tabular}

41. Vid.: HeRnÁNDEZ ESCAYOlA, M.C.: De tributo de la Iglesia a negocio para mercaderes: el arrendamiento de las rentas episcopales en la diócesis de Pamplona (siglo XVII).Pamplona: 2000, EUNSA. Éste trabajo ilustra muy bien el entramado económico y social que surge a través del arrendamiento de las rentas de la Iglesia. También resulta muy interesante por la proximidad geográfica y similitudes con la sede calagurritana.

42. ACDC 2261b/2. Los datos están tomados de un presupuesto de rentas y pagos fechado en 1648. Responden solo al concepto expresado de rentas arrendadas. A esto habría que sumar los cobros gestionados directamente o los que se percibían como renta fija en grano: por ejemplo, el mismo documento adjudica a Álava 1.928 fanegas de trigo y 1.192 de cebada. En cualquier caso excedería del propósito del presente trabajo hacer un estudio sobre las rentas del obispado en el periodo. La intención es solamente ilustrativa respecto de las oportunidades de negocio existentes en la gestión de las rentas diocesanas. 


\begin{tabular}{|l|r|l|r|}
\hline Arençana de abajo & 3.900.- & Viana & $22.000 .-$ \\
\hline $\begin{array}{l}\text { Baños de Riotovía, Anguiano, } \\
\text { Tovía, Sanmillán y Villorquido. }\end{array}$ & $4.700 .-$ & Yécora, Lambraça y Lanciego & $5.500 .-$ \\
\hline Aro y Cuzcurritilla & $4.200 .-$ & Cripán y Viñaspre. & $1.600 .-$ \\
\hline \multicolumn{2}{|l|}{ Monta lo arrendado....................... } & $149.450 .-$ \\
\hline
\end{tabular}

Otro capitulo lo sería el arrendamiento de los bienes raíces propios o gestionados por la Iglesia. En el caso de la SIC de Calahorra, estos comprenderían los anejos a beneficios y canonjías, los afectos a aniversarios, los de las capellanías de cuyo patronazgo gozase, los afectos a obras pías y a cofradías, los de titularidad de las tres mesas de la SIC, la comunal, la de aniversarios y la de la fábrica. Ésta última, aunque sin duda la más pobre de ellas, gozaba de un patrimonio considerable en bienes raíces, tal y como se detalla:

Heredades de la Fábrica de esta Santa Yglesia Catedral, apeadas por Manuel López, veedor en el año de $1719^{43}$

\begin{tabular}{|c|c|c|c|}
\hline Lugar o paraje & Cabida & Lugar o paraje & Cabida \\
\hline Villa de Autol & 3 f. y 4 c. & Río del Corona & $1.5 \mathrm{f}$. \\
\hline Rincón de Soto & Viña de $40 \mathrm{f}$. & Pressillas & 1f. y $3 \mathrm{c}$. \\
\hline Laguna & H. de 12 f. y 3 c. & San Lázaro & $1 / 2 \mathrm{f}$ \\
\hline Rijondo & $15 \mathrm{c}$. & Río de la Yniesta & $2 \mathrm{f}$. \\
\hline Barguilla & $2 \mathrm{f}$. & Planilla & 6 yugadas \\
\hline Barguilla & $22 \mathrm{c}$. & Pontigo & Linazar de $5 \mathrm{f}$. \\
\hline Ambilla & 5 f y 7 c. & Camino de Arnedo & Una hera \\
\hline Ambilla & $2 \mathrm{f} . \mathrm{y} 2 \mathrm{c}$. & Batán & $2 \mathrm{f}$. \\
\hline Ambilla & $8.5 \mathrm{c}$. & Fossal & Arboleda de 2,5 f. \\
\hline Ambilla & $1 \mathrm{f}$. & Rincón & $1 \mathrm{f}$ \\
\hline Torrescas & $2.5 \mathrm{f}$. & Balfenecín & $2 \mathrm{f}$. \\
\hline Carizente & $16 \mathrm{f}$. & Balfenecín & $1.5 \mathrm{f}$ \\
\hline El Araco & 2 f y 2 c. & Calahorra & $\begin{array}{l}\text { Casa tasada en } \\
16.000 \mathrm{r} \\
\end{array}$ \\
\hline Camino de Arnedo & Cañamar de $2 \mathrm{f}$ y $2 \mathrm{c}$. & Estanca & $3 \mathrm{f}$. \\
\hline Lampayana & $5 \mathrm{c}$ & Murillo & $2.5 \mathrm{f}$. \\
\hline Lampayana & $1 \mathrm{f} . \mathrm{y} 3 \mathrm{c}$. & Via Campo & $3 \mathrm{f}$. \\
\hline Lampayana & 3 f. y 7 c. & Torrescas & Viña de $11 \mathrm{p}$. \\
\hline Camino de Logroño & $1 \mathrm{fy} 2 \mathrm{c}$. & Torrescas & $1 \mathrm{f}$ \\
\hline Algarrada & $1.5 \mathrm{f}$. & Calahorra & Casa en renta de $36 \mathrm{~d}$ \\
\hline Total grano: & 83 f. y 5.5 c. & Viñas: & $40 \mathrm{f}$ y $11 \mathrm{p}$. \\
\hline Cañamar: & 2 f. y 2 c. & Linazar: & $5 \mathrm{f}$ \\
\hline Arboleda: & $2.5 \mathrm{f}$. & Otros & 2 casas y 1 era \\
\hline
\end{tabular}

f: fanega, c: celemín, d: ducados de vellón; r: reales de vellón.

43. Libro de Hacienda de la fábrica. ACDC: libro 254, folios 90-127. 
Por último citamos el desempeño de los cargos que existen en los templos, los más interesantes de los cuales son las mayordomías. En 16/III/1683, Juan Gómez Carrero, miembro de la ilustre familia de regidores de la ciudad y mayordomo de la mesa comunal de la SIC, es «alcanzado» en las cuentas que se le toman en nada menos que en 46.205 reales y 13 maravedís $^{44}$. El mayordomo se allana, ofreciendo los intereses de un año, y debiendo presentar como fiadores seglares a Pedro García de Jalón y a Juan Cordon Palacios. La abultada cifra en este caso hubo de ser devuelta, pero aún así es indicativa de las magnitudes manejadas por las mesas capitulares y del interés que avivaban en las familias calagurritanas.

Damos por establecido, por tanto, el atractivo que pudo despertar en dichos grupos la accesión a los puestos relevantes en los cabildos y mesas capitulares. Además, como conocemos ya por lo ejemplos descritos arriba que sí que existe dicha penetración, sólo queda establecer la estrategia mediante la cual pudieron llevarla a cabo.

En principio, los cargos en la Iglesia no estuvieron nunca en venta ${ }^{45}$. Es posible la presentación laical a determinados beneficios, como en determinados señoríos jurisdiccionales, el derecho de presentación de los reyes a los beneficios mayores o mediante la constitución de los llamados beneficios laicos, con reserva del derecho de presentación a los fundadores o a sus descendientes. La forma más sencilla de obtener dicho derecho de presentación y con él ingreso de los familiares no destinados al matrimonio, es mediante la constitución de capellanías perpetuas colativas, ya que, como veíamos, éstas se convierten en un verdadero beneficio eclesiástico con la conversión de su capital en bienes espirituales y la colación por el ordinario del lugar. La reserva del patronazgo de los mismos permitiría la preservación de la gestión de los bienes raíces por familiares y el derecho de presentación garantizaba la elección de los capellanes.

El origen del presente trabajo es una investigación en marcha sobre las capellanías en el contexto de La Rioja moderna. Durante la misma y al estudiar las fundaciones en Calahorra, se destacaron una serie de notas características que la hacían desviarse de los casos estudiados en otras poblaciones riojanas. En éstas, el origen social predominante son labradores ricos, mientras que en la sede episcopal se manifiesta la presencia de un núcleo proporcionalmente importante de regidores y familiares de estos, entre los fundadores y cargos de fundaciones calagurritanas, con una frecuencia de una serie de apellidos, relacionados entre si en las distintas capellanías. Éste fenómeno se pro-

\section{ACDC: $27 / 409 / 69$.}

45. Se pueden rastrear compensaciones a la obtención de determinados beneficios. Por ejemplo, el obispo Bernardo de Ontiveros solicita el 7/X/1661 2000 reales de plata para remitirlos a Madrid, el 26/X/1661 acusa recibo de los 2000 reales y de la petición del beneficio vacante en las parroquiales por don Antonio Zarzosa y, por último el 13/XI/1661 remite sus congratulaciones por la obtención del mismo (ACDC: 2717/12, 13 y 14). Sin embargo, tampoco se puede afirmar inequívocamente una relación de causaefecto entre ambos asuntos y, en cualquier caso la venta de beneficios no alcanza, ni de lejos, las cotas de degradación y de venta al mejor postor de los oficios civiles, característicos de ese momento de la monarquía hispánica. 
duce tanto por la constitución de nuevas capellanías como por la penetración en las renovaciones de capellanías preexistentes.

Asimismo se detecta un peso relativo algo mayor de los instrumentos financieros, primordialmente representados por censos, sobre los índices del resto de las poblaciones, constituidos fundamentalmente sobre bienes raíces, si bien este fenómeno puede explicarse en la incidencia de un contexto urbano sobre los medios de acumulación de capital.

Al situar un contexto temporal debemos señalar al siglo XVII y a la primera década del siglo XVIII. Antes, no se producen las desviaciones señaladas y, después de esa fecha no se registra ninguna nueva fundación en Calahorra.

En el Archivo Catedralicio y Diocesano de Calahorra se conserva documentación sobre 65 fundaciones entre los años 1412, la primera con constancia documental, y 1710, fecha de la última. Las mismas estan repartidas entre la Catedral (37) y las parroquiales de Santiago y San Andrés ${ }^{46}$ (28). De las que consta fehacientemente su fecha de fundación, la mayor parte se corresponden a los siglos XVI (21 fundaciones) y XVII (26), correspondiendo tres al XV y tres al XVIII. Del resto no consta en la documentación la fecha pero indiciariamente se puede concluir que también debieron fundarse en los siglos XVI y XVII, que serían, por tanto, los de mayor abundancia y frecuencia de estas instituciones.

En cuanto a las formas y métodos de fundación podemos apuntar que la mayoría de articulan mediante fundación testamentaria y que la práctica totalidad establece criterios de parentesco con el fundador ${ }^{47}$ para la provisión de sus cargos de patrono y capellán.

\section{Frecuencia de fundaciones (regidores)}

\begin{tabular}{|c|c|c|c|}
\hline Periodo & Consta & Indicios & Total \\
\hline S. XVI & 4 & 1 & 5 \\
\hline $1601 / 1650$ & 1 & 2 & 3 \\
\hline $1651 / 1710$ & 10 & 1 & 11 \\
\hline
\end{tabular}

De dichas 65 fundaciones, en al menos 20 de ellas, prácticamente una tercera parte, detalladas en el anexo 1 del presente, se logra establecer una relación directa con las familias más significativas del poder municipal calagurritano del periodo. En bastantes de ellas, además, con los mismos troncos familiares que habían acaparado la compra de cargos y los regimientos perpetuos arriba señalados y pertenecientes por tanto, a la oligarquía que está copando las instituciones de poder municipal. Este fenómeno, según se puede apreciar en el cuadro adjunto, se intensifica en el periodo $1651 / 1710$, lo que es congruente con un contexto español de reforzamiento de grupos

46. Como en los tiempos modernos ambas parroquias estaban unidas en un cabildo común, resulta difícil asegurar la pertenencia a una $u$ otra de cada una, -ya que a veces se indicaba que estaban instituidas en las parroquiales-. Lo más probable es que fueran más o menos similares en número.

47. Normalmente con preferencia de la descendencia masculina frente a la femenina e incluso excluyendo esta, como el caso de la fundada por Francisco de Leyva en 1650, que excluye la rama materna en la provisión de capellanes y de patronos, ADCD signaturas 27/3/1 y 27/3/11. 
de carácter oligárquico en todos los ámbitos de poder, estatal y local, ampliamente descrito por la historiografía. Aquí se apunta a una posible penetración de dichos grupos también en la Iglesia.

Asimismo debemos señalar que no solamente es valida la estrategia mediante la fundación de capellanías ex novo, también se puede logar idénticos resultados, usurpando los cargos de una ya existente ${ }^{48}$ o modificando sus características, como hace Andrés Gómez Carrero como patrón de la capellanía de Catalina García Fayo ${ }^{49}$, convirtiéndola en colativa, esto es, en un vehiculo adecuado para procurar la ordenación a su titulo de capellanes.

Éstos, gracias al beneficio eclesiástico, obtenido de tal forma, se colocaban en la situación de optar a desarrollar una carrera eclesiástica que les llevara a obtener y acumular beneficios e ingresos y a ocupar resortes de poder en la Iglesia. Éste es el caso, por ejemplo de Manuel de Paniagua, a quien el beneficio de que gozaba en San Andrés más las tres capellanías de que era titular le debieron garantizar una más que adecuada sustentación.

En cualquier caso, la lectura de los expedientes de provisión de capellanes permite en algunos casos ver, mediante las colaciones sucesivas los estados en que se encontraban los capellanes el acceder y al vacar, por muerte o renuncia, a sus capellanías.

Algunos ejemplos de promoción lograda por capellanes en su carrera

\begin{tabular}{|l|l|l|}
\hline \multicolumn{1}{|c|}{ Personaje } & $\begin{array}{c}\text { A la obtención de } \\
\text { la capellanía }\end{array}$ & \multicolumn{1}{|c|}{ Dignidad alcanzada } \\
\hline Francisco García de Jalón & $\begin{array}{l}\text { Clérigo de menores } \\
\text { ordenes }\end{array}$ & $\begin{array}{l}\text { Capellán del número y } \\
\text { comisionado de la hermandad de } \\
\text { capellanes de la SIC }\end{array}$ \\
\hline Juan Gómez Falcón & Capellán & $\begin{array}{l}\text { Presbítero beneficiado y abad de } \\
\text { San Andrés }\end{array}$ \\
\hline Antonio Gualite de Bovadilla & Capellán & Cura y beneficiado de la SIC \\
\hline Juan Gualite & Capellán & $\begin{array}{l}\text { Beneficiado y condotricio mayor } \\
\text { de San Andrés }\end{array}$ \\
\hline Julián Martínez & $\begin{array}{l}\text { Clérigo de menores } \\
\text { ordenes }\end{array}$ & $\begin{array}{l}\text { Clérigo presbítero y cura de } \\
\text { Campillo de Altobuey }\end{array}$ \\
\hline Manuel de Paniagua & $\begin{array}{l}\text { Clérigo de menores } \\
\text { ordenes }\end{array}$ & Beneficiado en San Andrés \\
\hline Francisco Antonio de Paredes & Menor de edad & Beneficiado en parroquiales \\
\hline Francisco de Paredes & Capellán & $\begin{array}{l}\text { Beneficiado en parroquiales y } \\
\text { canónigo de la SIC }\end{array}$ \\
\hline Simón de Urrutigoyti y Goñi & Menor de edad & $\begin{array}{l}\text { Canónigo y arcediano de } \\
\text { Berberiego en la SIC }\end{array}$ \\
\hline
\end{tabular}

48. Este puede ser el caso de la capellanía fundada por Juan Bautista López Collado, $\mathrm{N}^{\mathrm{o}} 15$ del anexo 1. Los provisores al nombrar a un miembro de los Gualite se sienten obligados a justificar su decisión por haber otros parientes con mejor derecho.

49. Anexo 1 capellanía $n^{\circ} 2$. 
Para comentar el éxito de la estrategia descrita, vamos retomar una historia ya comentada en el epígrafe en el que señalábamos las características del gobierno municipal de Calahorra. Se señalaba que las elecciones de los cargos municipales tenían lugar en la sala capitular de la SIC cada uno de enero. Esta situación anómala dura hasta el año de 1690 cuando, con motivo del pleito entre el cabildo de la SIC y el ayuntamiento por la elección de oficios municipales, el rey Carlos II emite una instrucción al alcalde mayor ordenando que las elecciones se hagan en las casas del ayuntamiento y se de traslado a la SIC para su provisión. Transcribimos un fragmento de la misma:«...por el dicho Juan Jiménez se hizo relación que alguno de los capitulares de esta ciudad eran afectos y apasionados de los canónigos de la Sta. Yglessia della, por el parentesco que tenían y que alguno de los dichos capitulares se habian jactado de que, para hacer las elecciones de oficios del año que viene de mil y seiscientos y noventa y uno, avían de vajar a la sala capitular de dicha Santa Yglessia en contravención de las leyes del reyno que disponían que dichas elecciones se hiciesen en las salas capitulares de las ciudades, villas y lugares del. Y para evitar los inconvenientes que podian resultar de que se hiciesen las dichas elecciones en la forma que se intentaba se mandase despachar provisión para que las dichas elecciones precisamente se yciesen en la cámara capitular de esta ciudad y no en otra parte.» ${ }^{50}$

\section{CONCLUSIONES}

En el periodo tratado coexisten en Calahorra dos núcleos de poder político. Estos dos núcleos no se encuentran equilibrados, sino que la catedral tiene un mayor peso debido a la extensión territorial de la diócesis y la mayor importancia de los intereses gestionados por la misma. El alejamiento de los obispos con su residencia habitual en Logroño, colocaba sin embargo, a la mesa capitular calagurritana en una situación peculiar en la que tampoco resultaba sencillo el imponerse al cabildo municipal. Por otra parte la residencia de los corregidores, también en Logroño, facilitaría una cierta autonomía a los regidores ciudadanos.

Obviamente, ambos ámbitos no dejaron de relacionarse, influirse y enfrentarse durante el periodo. Con un universo poblacional reducido en torno a las mil familias y a los cuatro mil habitantes se produce una lógica penetración de algunas familias en los resortes de poder de ambas instituciones. Estas familias, para acceder tenían que poseer determinados recursos, tanto económicos como de tiempo, para dedicarlos a alcanzar las posiciones privilegiadas en ambos ejes. La historiografía ha señalado ampliamente la utilización del mecanismo de la compra de oficios como el utilizado profusamente por las élites del siglo XVII como forma de acceder a posiciones de poder político y rentabilizarlo con las posibilidades que los mismos abrían.

La investigación realizada apunta como uno de los mecanismos utilizados por las clases privilegiadas calagurritanas fue la fundación y/o usurpación de capellanías perpetuas colativas.

50. ACDC: Sig. 2263b/4. 
La tesis del trabajo, no obstante, no es exactamente que los cargos municipales intentaran acceder a los cargos y oficios eclesiásticos, sino que un determinado grupo detentador de un importante poder económico desarrolla estrategias orientadas a acceder a los resortes de poder, civiles y eclesiásticos, indistintamente.

El ingreso en la carrera eclesiástica necesita durante el antiguo régimen de dos requisitos: los estudios necesarios y un beneficio a titulo del cual ordenarse. Las capellanías permiten la ordenación a su titulo de los capellanes y con ello el ingreso en la carrera eclesiástica, dado que fácilmente tendrían recursos para costear una educación quienes disponían del patrimonio necesario para constituir aquellas.

Los ejemplos aportados demuestran que resultó, al menos en determinados casos, una estrategia coronada por el éxito ya que, gracias a las mismas en varios casos se lograron optar a beneficios y canonjías e incluso las más altas dignidades en la Catedral y parroquiales de la ciudad riojana.

El personaje paradigmático de esta situación quizá sea don Pedro de Oñate y Murillas, miembro de dos importantes familias de regidores de la ciudad, los Oñate y los Murillas, sobrino político del regidor perpetuo don Pedro Paniagua y Arinzano y carnal de su esposa, doña Damiana López de Murillas, autora de la fundación ${ }^{51}$ más importante económicamente, -con 6000 ducados de principal-, de las registradas en la Calahorra moderna y a cuyo disfrute estaba llamado, tras su hermano Miguel, en segundo lugar. Pedro de Oñate cursó una exitosa carrera eclesiástica que le llevo a ocupar, primero, el cargo de vicario y provisor general del obispado y, después, la segunda dignidad en importancia, tras la prelatura episcopal, de la diócesis: el deanato de la Santa Iglesia Catedral de Calahorra.

\section{ANEXO 1. DETALLE DE LAS FUNDACIONES EN LA CATEDRAL Y LAS PARROQUIALES DE CALAHORRA ESTABLECIDAS POR REGIDORES Y FAMILIARES O INFILTRADAS POR LOS MISMOS}

Los siguientes párrafos se corresponden, resumidamente, con los extractos de la información recogida durante la investigación. Los mismos responden, básicamente, al nombre del fundador y año, instrumento de fundación, cargas y mecanismos de provisión de cargos, los datos económicos de las fundaciones y, naturalmente, el detalle de las signaturas donde están tomados. También se han recogido los datos de las colaciones y aquellos que, en general, pueden resultar interesantes al estudio. Lamentablemente la disparidad de tipos de expedientes y el largo tiempo pasado, han proporcionado una información irregular $\mathrm{y}$, en algunos casos, incompleta.

51. El autor del presente trabajo tiene publicado un trabajo sobre esta fundación: ARROYO VOZMEDIANO, J. L.: «Fundaciones Testamentarias de Damiana López de Murillas. Las capellanías de los Castañares y los Oñates a través de su instrumento de fundación» Kalakorikos, 12. 2007. Págs. 383-393. 


\section{$N^{o}$ 1. Juan Martínez de Yanguas ${ }^{52}$}

Regidor perpetuo de Calahorra, casado con Teodora de Carranza, sobrina de Fray Francisco de Carranza, arzobispo de Toledo. Testamento de 1593. Capellanía de 3 misas a la semana en San Andrés. Patrones, familiares, luego el cabildo de las parroquiales. Capellán que fuese pariente suyo más cercano en línea de varón. En el testamento no consta cantidad: ánima heredera universal, después de los días de su mujer y que se aplique el resto, después de mandas a la capellanía. En el expediente, fechado en 1632, se detallan los bienes: Olivar con 31 pies de olivos de 2 fanegas de sembradura, pieza de 4 fanegas de sembradura, pieza de fanega y media de sembradura, pieza con 11 pies de olivo, pieza de 2 fanegas de sembradura, pieza de 3 fanegas de sembradura, pieza de 4 fanegas de sembradura, pieza de anega y media de sembradura, tabla de 4 fanegas, pieza de 2 fanegas de sembradura, pieza de 1 fanega de sembradura, pieza de 5 fanegas de sembradura al río, pieza de 1 anega de sembradura, pieza de 8,5 fanegas de sembradura, pieza de 3 fanegas de sembradura, pieza de 1 fanega de sembradura, pieza de anega y media de sembradura, pieza de 3 fanegas de sembradura, pieza de 4 fanegas de sembradura, pieza de fanega y media de sembradura, pieza de 2 fanegas de sembradura, de 1 fanega de sembradura, pieza de 2 fanegas de sembradura, censos contra diversos particulares de 32d, 35d, 21d, y 70d. Una escritura de obligación de 29d.

\section{$N^{o}$ 2. Catalina García Fayo ${ }^{53}$}

Hacia1600. Deudos que obtienen la capellanía, regidores de la villa. Testamentaria. Iglesia de San Andrés, 3 misas a la semana. Capellanes de su linaje. No consta cantidad ni bienes, instituye a la capellanía por heredera universal. En documento de fecha 5/ III/1651, se recoge que «da de renta 30 ducados, poco más o menos, en cada año».

En 1641, ante Pedro García de Jalón, como notario apostólico, renuncia el capellán titular, Ignacio Gómez Falcón, a la misma, por sus muchas ocupaciones, por lo que pide que se le notifique a Andrés Gómez Carrero, regidor perpetuo de la ciudad y patrón de la capellanía. Como testigos firman Pedro de Paniagua, Francisco Díaz Esparza y Gabriel García de Jalón. Andrés Gómez Carrero, como patrón nombra a Manuel de Paniagua Arinzano, clérigo de menores ordenes, hijo legítimo de don Pedro de Paniagua Arinzano, regidor perpetuo de esta ciudad y de doña Ana Gómez Falcón, deuda de la fundadora.

El expediente que recoge la información es instruido a propósito de la solicitud que en 5/III/1651 realiza Andrés Gómez Carrero, -patrón y bisnieto de Celedón Gómez Falcón, primer patrón de la capellanía-, para que se haga colativa la capellanía y se haga colación de su primo Manuel de Paniagua. La erección de la capellanía en colativa se hace en $9 / \mathrm{III} / 1651$.

52. ACDC: $27 / 194 / 2$.

53. Ibíd.: 27/194/6. 


\section{$N^{o}$ 3. Hernán Pérez ${ }^{54}$}

Capellanía en Santiago. En el expediente consta el extravío del documento de fundación «por el largísimo tiempo que passó después de su fundación». Referencias a su fundación por testamento que no se conserva. Se remite a los libros de Santiago para establecer que al goce de la misma están llamados la familia de los Gualites.

En 1669 muere Antonio Gualite de Bovadilla, cura y beneficiado de la SIC, vacando la capellanía. Éste había sustituido la vacante por renuncia de Juan Gualite, beneficiado, condotricio mayor y abad de San Andrés.

Francisco Ruiz y Gualite opta a la capellanía y obtiene la colación en 2/III/1669.

\section{$N^{o}$ 4. Don Francisco Díaz de Esparza ${ }^{55}$}

Regidor de Calahorra. 1661, mediante escritura pública. Capellanía de misas de alba en domingos y festivos en San Andrés. Llama por capellán, al organista o sochantre, «por ser pobre su fábrica». Capital fundacional constituido sobre un censo de 820 ducados de Vellón.

El primer capellán fue Francisco Díaz de Medrano, sobrino llamado en el testamento, en pleito con Gerónimo López de Murillas, Marcos Rodríguez, Manuel de Paniagua, y Andrés Martínez Zarzosa, beneficiados en San Andrés y que se oponen a la colación del sobrino.

El origen del pleito está en la rectificación que el fundador hace sobre el derecho de presentación y patronazgo realizado en la fundación a favor del cabildo. En su testamento hace nombramiento de su sobrino, clérigo de menores órdenes, para que se ordene de mayores, mientras tanto encarga decir las misas a Manuel de Paniagua, su primo.

\section{$N^{o}$ 5. Andrés Gómez Carrero de Velasco y Antonia de Sanpedro Iustariz, su mujer ${ }^{56}$}

1656. Regidor perpetuo de Calahorra. Escritura publica de fundación, como ejecutor testamentario de Baltasar Gómez Carrero (regidor perpetuo de calahorra) y primer patrón de la capellanía. Capellanía en San Andrés, en la capilla de Sta Teresa, de dos misas a la semana a medio ducado de limosna. Capellanes, familiares. 9 censos por 1010 ducados, impuestos al 4\% según visita en 1714 .

Se llama por capellanes: $1^{\circ}$ a sus hijos; $2^{\circ}$ a los hijos y descendiente de don Juan Gómez Carrero de Velasco y de doña María Gómez Carrero de Velasco, sus hermanos; $3^{\circ}$ a los descendientes de Thomas Gómez Carrero, su primo carnal; $4^{\circ}$ a los hijos y descendientes de don Manuel y don Antonio Mancevo de Velasco sus sobrinos, hijos de don Gonzalo Mancevo de Velasco y de doña Ana Gómez Carrero, su prima carnal; $5^{\mathrm{o}}$ otros primos y, en general, al pariente más cercano de don Andrés Carrero Gómez de Velasco.

54. Ibíd.: 27/194/12.

55. Ibíd.: 27/195/1.

56. Ibíd.: 27/195/2, 27/195/12, 27/196/2, 27/196/9, 27/196/16, 27/196/21(visita). 
En 1671, nombrado capellán Francisco Mancevo de Velasco.

En 1684, Francisco García de Jalón, clérigo de menores órdenes, hijo de Manuel García de Jalón y de Ana María Gómez Carrero, nieto de Andrés García Carrero.

En 1704 obtiene la colación Diego Felipe Garcia de Jalón y Araciel.

\section{$N^{\circ}$ 6. José de Cabriada Roldán y Antonia de Roldán y Texada, su mujer ${ }^{57}$}

Escritura pública de 1673. Capellanía de diez misas al año en Santiago. Capellanes, familiares. Capital: 600 ducados de principal y 30 de renta; Pieza de 2 fanegas de sembradura, 100 ducados; pieza de una fanega y media de sembradura cañamar, 150 ducados; pieza de 2 fanegas de sembradura, 100 ducados; pieza de 2 fanegas de sembradura cañamar, 150 ducados; pieza de 3 fanegas de sembradura, 100 ducados.

Por capellán llama a sus hijos Antonio, primero, y, Francisco, en segundo lugar, estudiantes en la Universidad. En tercer lugar a su otro hijo, Thomás. Después a sus otros hijos y descendientes. Patrones hijos y descendientes prefiriendo el mayor al menor. En escritura se recogen las renuncias de la mujer a dote y arras.

El fundador aparece en 1674 como regidor por el estado de los fijosdalgo $0^{58}$, también se documenta un pleito con el cabildo de la SIC, por ofensas al mismo, visto ante la Real Audiencia de Valladolid ${ }^{59}$.

\section{$N^{\circ} 7$. Juan Félez y Antonia Pérez ${ }^{60}$}

1672. Escritura pública. Capellanía en S. Andrés. Primer capellán su hijo, Manuel Félez, después otros hijos, parientes y deudos. 1000 ducados de principal (casa, piezas por 12 fanegas y 1 viña). El fundador aparece nombrado como fiel almotazán en las elecciones de oficios anuales de 1 de enero de $1667^{61}$. A la muerte de Manuel Félez en 1690 opta a la misma, y la consigue, Joseph de Villarreal (fundador de la capellanía $\mathrm{n}^{\circ}$ 17), por presentación de Joan Guindo y Ana María Félez, yerno e hija de los fundadores, por las «condiciones del susodicho» $\mathrm{y}$ «no haber deudos y parientes que puedan ejercerla».

\section{$N^{o} 8$. Simón de Urritigoyti y Leandra Roldán, su mujer ${ }^{62}$}

1640. Escritura publica. Regidor perpetuo de Calahorra. Capellanía en Santiago de 12 misas al año. Capellán, hijos y descendientes, luego «el pariente más cercano que sea de buena vida y costumbres». Una casa y cercado. Un cañamar de 8 fanegas.»Libres de censos e hipotecas». Capellanía compatible con «renta eclesiástica, grande o pequeña», según recoge expresamente el documento de fundación, en el cual se llama a su hermano, para que la usufructúe, Diego Francisco de Urritigoyti canónigo

57. Ibíd.: 27/195/4.

58. AHMC: AA 125/1, 4/1/1678.

59. ACDC: $2817 / 15$.

60. Ibíd.: 27/196/1.

61. Acta transcrita por García CALOnge, M. (op. cit.), Págs. 111-118.

62. ACDC: 27/196/4, 27/196/5, 27/196/14 y 27/196/17. 
de la SIC y la trasmita a los hijos de su otro hermano, Pedro de Urritigoyti. También hace referencia a otro hermano del fundador, Jerónimo Julián Urritigoyti, arcediano de Berberíego.

En 1653 aparece Jerónimo Joseph de Urritigoyti y Goñi, arcediano de Berberíego, visitando la capellanía siendo capellán el sobrino del fundador (y hermano del visitador), Simón de Urritigoyti y Goñi.

En 1692, por muerte del capellán, Simón de Urritigoyti y Goñi, canónigo y arcediano de Berberíego en la SIC, opta a la colación su hermano Francisco, beneficiado en Carmona, que la obtiene en 1693. Resulta curioso como fueron heredando de tío a sobrino el arcedaniato referido.

\section{$N^{o}$ 9. Damiana Lopez de Murillas ${ }^{63}$}

Viuda de don Pedro de Paniagua y Arinzano, regidor perpetuo de Calahorra. Fundación en 1710 en escritura publica basada en un testamento de 1708. Dos capellanías, una en San Andrés y otra en Santiago. Los capellanes y los patronos, elegibles entre dos troncos de sobrinos de la fundadora: los Oñate en S. Andrés y los Castañares en Santiago. San Andrés (Oñates): censos 21.450 r bienes raíces $11.240 \mathrm{r}$ Total capital fundacional 32.690 reales. Santiago (Castañares): censos $22.550 \mathrm{r}$ bienes raíces 9.960 r. Total capital fundacional 32.510 reales.

Además de la figura del difunto marido, la fundadora es miembro de una familia, los Lopez de Murillas, permanentemente presentes en los oficios y cargos municipales del periodo. Uno de los troncos de sobrinos, Los Oñate también se corresponde con una de las familias habituales del regimiento calagurritano, dándose el caso que entre los llamados a gozar de la capellanía está el que en el momento de la fundación era el Vicario General del Obispado, Pedro Oñate y López de Murillas, quien llegaría a ser deán de la SIC.

\section{$N^{o}$ 10. Rodrigo Álvarez de Motrico ${ }^{64}$}

1553. Racionero de la SIC. (Referencia a parentela con los Gómez Carrero, Regidores de la ciudad). Capellanía en la SIC «que llaman de los Motrico». No se halla ni el testamento ni escritura de fundación, según visita de 1608 (4214/1). Carga de una misa a la semana. En las provisiones se emplea el parentesco como argumento. Vale 7000.- maravedís de renta.

En 1608 se adjudica a Joan Gómez Falcón como pariente más cercano del fundador, quien alega que fue su rebisabuelo.

En 1662 la capellanía vaca por muerte del Licenciado Joan Gómez Falcón, clérigo presbítero, abad y beneficiado de San Andrés. Se adjudica a don Manuel de Paniagua y don Pedro Gómez Falcón, parientes en $5^{\circ}$ grado del fundador.

63. Ibíd.: 27/196/22.

64. Ibíd.: 4214/1-5. 


\section{$N^{o}$ 11. Ángela Lopez de Paredes ${ }^{65}$}

C.a. mediados del XVII. Capellanía en la SIC. No se conserva documento de fundación ni referencia a los bienes ni a la carga de misas.

En 1682 don Antonio de Paredes (casado con Ana Maria López de Murillas), «abogado de los reales consejos y regidor preeminente de esta ciudad» solicita canónica colación de su hijo Francisco Antonio de Paredes, que consigue. Aparece una referencia al hermano del padre, Francisco de Paredes, que fue capellán de la misma, canónigo de la SIC y beneficiado en las iglesias parroquiales.

En 1695, por muerte de Francisco Antonio de Paredes, «beneficiado que fue en las parroquiales», se hace canónica institución a José de Paredes, clérigo de menores órdenes y hermano del anterior.

\section{$N^{\circ}$ 12. Fadrique Ramiro de Arellano ${ }^{66}$}

Hijo de los condes de Aguilar. Capellanía para fijosdalgo, elegidos por el prior y los 8 caballeros del Estado de los fijosdalgo de la ciudad. Testamento en 1540. Capellanía en la SIC llamada de los fijosdalgo, de misas diarias, consta rebaja a 35 misas en 1664 y que produce una renta de 205,5 reales al año.

En 1640 se produce la colación en don Gerónimo López de Murillas, clérigo de menores órdenes y ya capellán de la capellanía del licenciado Valdeolivas.

En 1652 vaca por dejación del anterior y la solicita su sobrino, Gabriel Lopez de Murillas, estudiante, «para que se ordene a titulo della». Antonio Gualite de Bovadilla, cura de la SIC, certifica su bautismo y que es hijo de don Diego López de Murillas (regidor) y de doña Águeda de Paredes.

En 1699, don Gabriel Lopez de Murillas, beneficiado y condotricio mayor de las parroquiales de Calahorra, hace dejación de la capellanía que obtiene don Juan Francisco García de Jalón y Lacanal, capellán de la SIC.

\section{$N^{o}$ 13. Pedro Martinez de Lacanal ${ }^{67}$}

Arcipreste de Camero Nuevo, canónigo de la SIC, beneficiado de diversas iglesias. No consta fecha exacta de fundación, podría ser hacia 1625/50, según se deduce de la primera sustitución en 1668. Testamentaria. Capellanía en la SIC de 3 misas a la semana. Primer capellán, un sobrino, luego pariente que sea clérigo presbítero. Patrón, primero un hermano del primer capellán, luego descendientes. Imputada una renta de 100 ducados sobre sus censos y propiedades, que no constan. En testamento aparece una casa en usufructo vitalicio a su hermana que luego habría de revertir a la capellanía.

En 1672 es patrón Diego de Lacanal, regidor; en 1676 lo es Juan Francisco García de Jalón, escribano del número, casado con Josepha de Lacanal.

65. Ibíd.: 4214/8-9.

66. Ibíd.: 4215/1-5.

67. Ibíd.: 4216/13-16. 


\section{$N^{o}$ 14. Fernando Gómez de Velasco y Pedro García de Jalón ${ }^{68}$}

Arcediano de Vizcaya y escribano del cabildo y del ayuntamiento de dicha ciudad número y aduana della, respectivamente. Cuñados y fijosdalgo de esta ciudad. Documento público.1663. 20 misas al año en la SIC y altares de $\mathrm{N}^{\mathrm{a}} \mathrm{S}^{\mathrm{a}}$. Patronos, deán y cabildo de la SIC. Capellán $1^{\circ}$ Gerónimo García de Jalón (hijo) luego parientes suyos. Capellanía acumulable a otros beneficios y rentas, grandes o pequeños. Una casa; una viña de 6 peonadas; una heredad de 4 fanegas; otra de 3 fanegas de sembradura; otra de 1,5 fanegas de cañamar; otra de 5 fanegas; otra de 6 fanegas de sembradura; otra de 2 fanegas, otra de 1,5 fanegas.

\section{$N^{o}$ 15. Licenciado Juan Bautista López Collado ${ }^{69}$}

Testamento de 1662. Clérigo presbítero, arcipreste del sagrario de la SIC de Málaga. 40 misas en S. Andrés. Capellanes, los parientes más cercanos. Capellán ordenado de primera tonsura, con obligación de ordenarse de mayores y compatible con otro beneficio. Bienes: dos casas, dos viñas (18 peonadas) y 8 piezas (23 fanegas), tasadas en 1056 ducados.

En 1668, don Joseph de Gualite de Bovadilla, «regidor desta ciudad», como padre y legítimo administrador, presenta a su hijo Joseph Francisco de Gualite, quien obtiene la capellanía. En el expediente de colación, los provisores (arcediano de Vizcaya y otro canónigo) justifican su elección frente a otros pretendientes, parientes más cercanos y, aparentemente, con mejor derecho, en la facultad concedida al obispo en la fundación y en que la residencia en Calahorra de Francisco de Gualite le hace más idóneo frente a la residencia fuera de los otros candidatos (Murcia).

En 1705 vaca la capellanía por muerte de Joseph Francisco de Gualite. Su padre, aún vivo, presenta a otro hijo, menor en días, Miguel Joseph de Gualite, que la obtiene. En 1726, la obtiene Francisco de Gualite por vacante por matrimonio del anterior.

\section{$N^{o}$ 16. Martín de Mendizábal de Medrano y Bazán ${ }^{70}$}

1672. Canónigo de la SIC y beneficiado en Santiago y S. Andrés. (Familia de caballeros de la orden de Alcántara y de Pedro Medrano Muñiz, regidor perpetuo de la ciudad). Documento público. Capellanía en la SIC de 216 misas rezadas al año. Otorgante 1er capellán, luego familia Medrano. Capellanía compatible con otras rentas y para ordenados de mayores. Un Juro de 3000 ducados al 5\% contra el servicio real ordinario y extraordinario de la ciudad de Valladolid, que renta 150 ducados y a deducir 10 ducados para la fabrica de la SIC.

\footnotetext{
68. Ibíd.: 4217/2.

69. Ibíd.: 4215/6-9.

70. Ibíd.: 4217/4.
} 


\section{$N^{o}$ 17. Josef Villarreal ${ }^{71}$}

1709. Presbítero y capellán en la SIC y en la parroquial de S. Andrés. Testamento. Misa en la SIC todos los días de fiesta. Patronazgo al mayorazgo de don Manuel Santiago de Fuenmayor (Casas y vínculo de Fuenmayor). Primer capellán hermano clérigo del fundador, luego otorga el derecho de presentación al mayorazgo. Cesión de casas, bienes y viñas al Mayorazgo con carga de hacer decir las misas. Limosna de 5,5 reales por misa. Este fundador es el capellán que obtiene la fundada por Juan Félez $\left(\mathrm{N}^{\mathrm{o}} 6\right)$.

\section{$N^{\circ} 18$. Ana de Aras, mujer de Miguel García de Jalón, regidor de Calahorra ${ }^{72}$}

1665. Testamento. Capellanía en la SIC de 80 misas al año. Patronos, deán y cabildo. Capellanes parientes suyos más próximos, prefiriendo el varón a la hembra e incluyendo los hijos que pudiera tener su marido tras su muerte. 1 cañamar de 3 fanegas; 10 celemines de sembradura; viña de 8 peonadas; otra viña de 8 peonadas; otra viña de 5 peonadas. La $1 / 2$ de un horno de cocer pan. $1^{\circ}$ reserva el usufructo vitalicio a su viudo. No se puede seguir la evolución en los primeros años de esta fundación ya que los expedientes que se conservan son renovaciones del primer tercio del s. XIX.

\section{$N^{0}$ 19. María Zapata ${ }^{73}$}

Testamento de 1668. Viuda de Domingo Cillero. Dos misas a la semana en San Andrés y Santiago. Un sobrino, Juan Cillero, primer capellán, luego parientes. Tres mil ducados de principal en diversos censos sobre los que se asigna al capellán renta de 40 fanegas de trigo, 200 cantaras de vino y 24 cantaras de aceite. Primer patrón, Diego Zapata clérigo presbítero beneficiado en las parroquiales.

En los archivos solamente de conserva un expediente de provisión que incluye el testamento. La importancia de la fundación apunta a que se trata de una miembro de la importante familia de los Zapata con diversos personajes ostentando cargos municipales durante todo el siglo XVII, como Matheo Zapata, Procurador general en 1667 o Diego Zapata, regidor en diversas ocasiones. El apellido Cillero de su difunto marido también es habitual, documentándose un Juan Cillero como alcalde de la Santa Hermandad de ese mismo año de $1667^{74}$.

\section{$N^{\circ}$ 20. María Fernández de Echauz ${ }^{75}$}

Doncella. Escritura pública de 1549. Capellanía en la SIC de 3 misas a la semana. Los familiares presentaran a los capellanes al cabildo. "Está fundada la capellanía sobre 31 fanegas de tierra de sembradura las cuales rentan 17 fanegas de trigo en

71. Ibíd.: 4217/10.

72. Ibíd.: 4217/18.

73. Ibíd.: 27/195/5.

74. AHMC: Elecciones de oficios municipales, Actas del Ayuntamiento de 1/1/1667.

75. ACDC: 4213/13-15. 
cada un año». El apellido Echauz es uno de los habituales en los oficios municipales, teniendo numerosos representantes siendo el más importante Jerónimo de Echauz quien compro de Felipe IV la preeminencia en su oficio de regidor y llego incluso a nombrar teniente a su hijo Martin de Echauz.

\section{ANEXO 2. TABLA DE PARENTESCOS}

La siguiente tabla intenta, en lo posible, aclarar la maraña de relaciones de parentesco entre los distintos troncos familiares y los oficios y cargos desempeñados por principales personajes de las fundaciones antes descritas, atendiendo principalmente al primer apellido como criterio de atribución. En el cuadro estan señaladas las principales relaciones de parentesco, aunque no todas. Las referencias precedidas del símbolo \# están referidas al número de capellanía del anexo 1.

\begin{tabular}{|c|c|c|}
\hline $\begin{array}{c}\text { Tronco } \\
\text { Familiar }\end{array}$ & Seglares & Clérigos \\
\hline $\begin{array}{l}\text { García de } \\
\text { Jalón }\end{array}$ & $\begin{array}{l}\text { 1. Pedro García de Jalón, escribano } \\
\text { del número y aduana, notario apostólico, } \\
\text { procurador general y síndico del común, } \\
\text { fundador \#14, padre de } 26 . \\
\text { 2. Manuel García de Jalón, marido } \\
\text { de } 9 . \\
\text { 3. Miguel García de Jalón, regidor, } \\
\text { primer patrón \#18. } \\
\text { 4. Juan Francisco García de Jalón, } \\
\text { escribano del número, marido de } 19, \\
\text { patrón \#13. }\end{array}$ & $\begin{array}{l}\text { 26. Jerónimo Garcia de Jalón y } \\
\text { Velasco, capellán de \#14, hijo de } 1 \text {, } \\
\text { sobrino de } 25 . \\
\text { 27. Francisco García de Jalón, hijo } \\
\text { de } 2 \text { y de } 9 \text {, nieto de 5, capellán \# } \\
\text { 3, capellán del número de la SIC, } \\
\text { comisionado de la hermandad de } \\
\text { capellanes de la SIC. } \\
\text { 28. Diego Felipe García de Jalón y } \\
\text { Araciel, capellán \#3. } \\
\text { 29. Juan Francisco García de Jalón y } \\
\text { Lacanal, capellán \#12, hijo de } 4 \text { y } 19, \\
\text { sobrino de } 18 . \\
\end{array}$ \\
\hline $\begin{array}{l}\text { Gómez } \\
\text { Carrero }\end{array}$ & $\begin{array}{l}\text { 5. Andrés Gómez Carrero, regidor } \\
\text { perpetuo, patrón \# } 2 \text { y \#5, deudo de } 7 \text {, } \\
\text { procurador general y síndico del común. } \\
\text { 6. Thomas Gómez Carrero, regidor de } \\
\text { la ciudad, primo carnal de } \mathrm{N}^{\mathrm{o}} 5 \text {. } \\
\text { 7. Baltasar Gómez Carrero, regidor } \\
\text { perpetuo, fundador \# 5. } \\
\text { 8. Ana Gómez Carrero, prima de 5, } \\
\text { madre de } 25 \text {. } \\
\text { 9. Ana María Gómez Carrero, hija de } \\
\text { 5, esposa de } 2 \text {. }\end{array}$ & $\begin{array}{l}\text { 30. Gonzalo Gómez Carrero, abad en } \\
\text { San Andrés, capellán \#5 }\end{array}$ \\
\hline $\begin{array}{l}\text { Gómez } \\
\text { Falcón }\end{array}$ & $\begin{array}{l}\text { 10. Celedón Gómez Falcón, patrón \# 2, } \\
\text { bisabuelo de } 5 \text {. } \\
\text { 11. Ana Gómez Falcón, } 1^{\text {a }} \text { mujer de } 21 \text {, } \\
\text { madre de } 44 \text {. }\end{array}$ & $\begin{array}{l}\text { 31. Juan Gómez Falcón, capellán \#2 } \\
\text { y \#10, presbítero beneficiado y abad de } \\
\text { San Andrés. } \\
\text { 32. Pedro Gómez Falcón, capellán \#10. }\end{array}$ \\
\hline
\end{tabular}




\begin{tabular}{|c|c|c|}
\hline Gualite & $\begin{array}{l}\text { 12. Joseph de Gualite de Bovadilla, } \\
\text { regidor por el estado de hombres } \\
\text { buenos, hermano de } 13 \text { y } 34 \text {. } \\
\text { 13. Diego Gualite de Bovadilla, regidor } \\
\text { por el estado de hombres buenos, } \\
\text { hermano de } 12 \text { y } 34 \text {. }\end{array}$ & $\begin{array}{l}\text { 33. Juan Gualite, beneficiado, } \\
\text { condotricio mayor y abad de San } \\
\text { Andrés, capellán \# } 3 \text {. } \\
\text { 34. Antonio Gualite de Bovadilla, cura } \\
\text { y beneficiado en la SIC, capellán \#3, } \\
\text { hermano de } 12 \text { y } 13 \text {. } \\
\text { 35. Francisco Ruiz y Gualite, capellán } \\
\# 3 \\
\text { 36. Joseph Francisco de Gualite, } \\
\text { capellán \#15, hijo de } 12 \text {, sobrino de } 13 \text {. } \\
\text { 37. Miguel Joseph de Gualite capellán } \\
\# 15 \text {, hijo de } 12 \text {, sobrino de } 13 \text {. }\end{array}$ \\
\hline & $\begin{array}{l}\text { 14. Diego López de Murillas, marido } \\
\text { de } 23 \text {, padre de } 38 \text {, hermano de } 39 . \\
\text { 15. Damiana López de Murillas, } 2^{\text {a }} \\
\text { mujer de } 21 \text {, fundadora } \# 9 \text {. } \\
\text { 16. Francisco López de Murillas, } \\
\text { regidor por el estado de los fijosdalgo, } \\
\text { alcalde mayor. } \\
\text { 17. Ana María López de Murillas, } \\
\text { mujer de } 22 \text {. }\end{array}$ & $\begin{array}{l}\text { 38. Gabriel López de Murillas, } \\
\text { capellán \#12, hijo de } 14 \text { y } 23 \\
\text { 39. Gerónimo López de Murillas, } \\
\text { capellán \#12, hermano de } 14 \text {, tío de } 38 \text {, } \\
\text { beneficiado en San Andrés. }\end{array}$ \\
\hline Lacanal & $\begin{array}{l}\text { 18. Diego de Lacanal, regidor, patrón } \\
\text { \#13. } \\
\text { 19. Josepha de Lacanal, hermana de } \\
18 \text {, mujer de } 4 .\end{array}$ & $\begin{array}{l}\text { 40. Pedro de Lacanal, arcipreste de } \\
\text { Camero Nuevo, canónigo de la SYC, } \\
\text { fundador } \# 13 \text {. }\end{array}$ \\
\hline Oñate & $\begin{array}{l}\text { 20. Francisco de Oñate, regidor por el } \\
\text { estado de los fijosdalgo. }\end{array}$ & $\begin{array}{l}\text { 41. Miguel Oñate y Murillas, capellán } \\
\# 9 \text {, sobrino de } 15 \text { y } 21 \text {, hermano de } 42 \\
\text { y } 43 \text {. } \\
\text { 42. Pedro Oñate y Murillas, presbítero } \\
\text { beneficiado en las parroquiales, patrón } \\
\# 9 \text {, sobrino de } 15 \text { y } 21 \text {, hermano de } 41 \\
\text { y } 43 \text {. } \\
\text { 43. Joseph Oñate y Murillas, vicario } \\
\text { y provisor general del obispado, más } \\
\text { tarde deán de la SIC, sobrino de } 15 \text { y } 21 \text {, } \\
\text { hermano de } 41 \text { y } 42 \text {. }\end{array}$ \\
\hline Paniagua & $\begin{array}{l}\text { 21. Pedro de Paniagua y Arinzano, } \\
\text { regidor perpetuo, casado con } 15 \text { y con } \\
21 \text {, padre de } 44 \text {, tío de } 41,42 \text { y } 43 \text {. }\end{array}$ & $\begin{array}{l}\text { 44. Manuel de Paniagua, capellán \# } 2 \\
\text { y \#10, beneficiado en San Andrés, primo } \\
\text { de } \mathrm{N}^{\circ} 5 \text {, hijo de } \mathrm{n}^{\circ} 21 \text { y de } 11 \text {. }\end{array}$ \\
\hline
\end{tabular}




\begin{tabular}{|c|c|c|}
\hline Paredes & $\begin{array}{l}\text { 22. Antonio de Paredes, abogado de los } \\
\text { reales consejos, regidor por el estado de } \\
\text { fijosdalgo, marido de } 17 \text {, padre de } 46 \text { y } \\
\text { 47, hermano de } 45 \text {. } \\
\text { 23. Águeda de Paredes, mujer de } 14 \text {, } \\
\text { madre de } 38 \text {. }\end{array}$ & $\begin{array}{l}\text { 45. Francisco de Paredes, capellán } \\
\# 11 \text {, beneficiado en las parroquiales y } \\
\text { canónigo de la SIC, hermano de } 22 \text {, tío } \\
\text { de } 46 \text { y } 47 \text {. } \\
\text { 46. Francisco Antonio de Paredes, } \\
\text { capellán \#11, beneficiado en las } \\
\text { parroquiales, hijo de } 22 \text { y } 17 \text {, sobrino } \\
\text { de } 45 \text {. } \\
\text { 47. José de Paredes, capellán \#1 hijo de } \\
22 \text { y } 17 \text {, sobrino de } 45 \text {. }\end{array}$ \\
\hline Urritigoyti & $\begin{array}{l}\text { 24.Simón de Urritigoyti, regidor } \\
\text { perpetuo, fundador \# } 8\end{array}$ & $\begin{array}{l}\text { 48. Jerónimo Julián de Urritigoyti, } \\
\text { arcediano de Berberiego, hermano de } \\
24 . \\
\text { 49. Diego Francisco de Urritigoyti, } \\
\text { canónigo de la SIC, capellán \#8, } \\
\text { hermano de } 24 \text {. } \\
\text { 50. Jerónimo Joseph de Urritigoyti } \\
\text { y Goñi, arcediano de Berberiego, hijo } \\
\text { de } 24 . \\
\text { 51. Simón de Urritigoyti y Goñi, } \\
\text { capellán \#8, arcediano de Berberiego, } \\
\text { hijo de } 24 \text {. } \\
\text { 52. Francisco de Urritigoyti y Goñi, } \\
\text { beneficiado en Carmona, capellán \#8, } \\
\text { hijo de } 24 \text {. }\end{array}$ \\
\hline Velasco & $\begin{array}{l}\text { 25. Manuel Mancevo de Velasco, } \\
\text { regidor por el estado de hombre buenos, } \\
\text { sobrino de } \mathrm{N}^{\mathrm{o}} 5 \text {, hijo de } 8\end{array}$ & $\begin{array}{l}\text { 53. Francisco Gómez de Velasco, } \\
\text { fundador \# } 13 \text {, arcediano de Vizcaya, } \\
\text { cuñado de } N^{\circ} 1 \text {. } \\
\text { 54. Francisco Mancevo de Velasco, } \\
\text { capellán de \# 5, hijo de } 25\end{array}$ \\
\hline
\end{tabular}

\section{ANEXO 3.TRASCRIPCIÓN DE UN FRAGMENTO DE LA FUNDACIÓN DE LA CAPELLANÍA DE DOÑA DAMIANA LÓPEZ DE MURILLAS ${ }^{76}$}

«Primeramente nombran por patrono de esta dicha capellanía a don Gabriel López de Murillas, presbitero beneficiado y condotricio mayor de dicha universidad de parroquiales y, después de sus días, a doña Josepha López de Murillas, su hermana, y después de los días de la susodicha, nombran por patrono perpetuo al poseedor que fuese del mayorazgo que fundó el dicho don Joseph de Oñate, para don Manuel de Oñate y sus descendientes.

Yttem nombran por primero capellán desta dicha capellanía al dicho don Joseph de Oñate y Murillas y, después de sus días, a de gozar la dicha capellanía el dicho doctor don Pedro de Oñate y Murillas, su hermano, y en bacando la dicha capellanía

76. Ibíd.: 27/196/22, folios 15-17. Escritura de fundación de capellanía efectuada por los cabezaleros de doña Damiana López de Murillas, sus sobrinos don Joseph de Oñate y Murillas y don Manuel de Castañares. 
por muerte del dicho don Joseph y señor doctor don Pedro de Oñate y Murillas, primero y segundo llamado, o por renuncia y dejación que della hiciere, o por otra cualquiera causa, nombran por sucesoras de dicha capellanía a doña Josepha de Oñate y Murillas, religiosa novicia en el conbento de San Agustín de la ciudad de Logroño y a doña Manuela de Oñate y Murillas, para que partan sus réditos y rentas desta dicha capellanía, llebando la dicha doña Josepha las dos partes y la dicha doña Manuela la tercera parte, cumpliendo cada una de las susodichas con hacer decir y celebrar las misas a lo que recivieren.

Y si faltase cualquiera de las dichas doña Josepha y doña Manuela de Oñate, en lugar de la que faltare, entre a gozar la rrenta que aquella gozare de dicha capellanía doña Águeda de Oñate y Murillas, soltera, por los días de su vida y cumpla con las misas y cargas de la dicha capellanía en la forma rreferida. Y después de los días de las susodichas nombran inmediatamente para el goze de dicha capellanía a los hijos de don Manuel de Oñate y Murillas, y sus descendientes por baronía, de manera que el que descendiere de barón sea preferido al que descendiere de hembra aunque el que descendiere de barón sea más remotto. Y acabada esa línea nombran, y llaman al gozo de dicha capellanía a los hixos y descendientes de lexitimonio de doña Ana María de Oñate y Murillas, muger legítima de don Emeterio de Arinzana y Pereda, y por quanto don Andrés de Arinzana Oñate y Murillas, hixo lexitimo de los susodichos se halla manco de un brazo y ymposibilitado para recivir las ordenes, mobidos de la piedad y que tenga algún socorro para mantenerse, le dispensaron en que pueda gozar la dicha capellanía, en llegando el casso de su turno, todo el tiempo que conserbare la soltería y luego, al punto que passe al estado del matrimonio, baque la dicha capellanía, y passe a los siguientes llamados.

Y acabada la dicha descendencia de los hixos y descendientes de la dicha doña Ana María de Oñate y Murillas, nombran por sucesores de dicha capellanía a los hijos y descendientes de la dicha doña Manuela y, después, a los de dicha doña Águeda.

$Y$ acabadas las dichas descendencias, nombran por sucesores en dicha capellanía a Don Chrisanto Joseph García de Jalón y Murillas, hijo lexítimo de don Joseph García de Jalón y de doña Theresa de Oñate y Murillas, ya difunta, y sus hijos y descendientes y a todos los demás descendientes de los dichos don Pedro de Oñate y doña Ana María López de Murilla, padres lexítimos del dicho don Joseph de Oñate y Murillas, otorgante». 